The author studies the most important points of contact between the poetry of Hipponax and the Aristophanic Comedy. Accordingly, some aspects of vocabulary (word-composition, obscene language, colloquial words, cookery-terms, zoological vocabulary and "noms parlants»), contents, structures and other thematic relations are analysed.

1. El fundamento de las ideas que desarrollaremos a continuación es el convencimiento de que existe una línea de continuidad entre la poesía de los yambógrafos de la Jonia arcaica y la comedia ática. El fenómeno es conocido; a ningún lector de ambos géneros pueden escapar las continuas resonancias que se dan en numerosos aspectos entre ambos géneros. Algún especialista ha llegado a afirmar que "la $\varkappa \omega \mu \omega \delta i \alpha$ es en verdad sólo una nueva versión espontánea, pero totalmente paralela, de la antigua poesía yámbica jonia» ${ }^{1}$. Incluso a la hora de hacer frente al problema de los orígenes de la comedia da la impresión de que uno de los pocos elementos constituyentes primigenios de aquélla que permanece indiscutible es el que procede de la savia aportada por el yambo; y no sólo porque lo diga Aristóteles cuando sostiene que, nacidas ya la tragedia y la comedia, surgieron los comediógrafos de los yambógrafos, igual que los trágicos fueron los continuadores de los autores épicos ${ }^{2}$. Aunque tales afirmacio-

* El presente título evoca intencionadamente una gran contribución a la crítica hiponactea: E. Degani, «Ipponatte parodico», $M C r$ 8/9, 1973/4, pp. 141-167. Las citas de los fragmentos corresponden a la edición de M.L. West, Iambi et Elegi Graeci, Oxford 1978 , I, pp. 109-171. No obstante, subrayamos desde ahora el gran valor de la reciente edición de E. Degani (H. Degani), Hipponax, Testimonia et Fragmenta, Leipzig 1983 , si bien hemos preferido mantener la numeración de la edición oxoniense, de más extendido uso en estos momentos. Las discrepancias serán notadas en su lugar.

1 A. Gerhard, "Iambographen», RE IX, 1916, cols. 651 ss. (cita tomada de col. 660 , 11. 20-23).

2 Poet. IV 1449 a 4. 
nes no vayan acompañadas del suficiente detalle y justificación, demuestran cómo entre los mismos griegos cualquier reflexión de tipo genérico sobre la comedia les conducía también a la relación con el yambo de manera casi inmediata y con un valor de evidencia palmaria. De suerte que casi se puede hablar de intuiciones que llevan automáticamente a establecer esa conexión cuando se ha leído a los autores representativos de ambos géneros. En cierto modo esto es lo que ha ocurrido con frecuencia en la filología moderna, ya que, con notables excepciones, no abunda la fundamentación sistemática de tan patente relación, que, en algunos temas, era absolutamente necesaria ${ }^{3}$.

Tal es el caso del lenguaje obsceno, esencial en la comedia. No es mera rutina que Jeffrey Henderson, en su excelente investigación titulada The Maculate Muse $e^{4}$ haya dedicado en su primer capítulo unas páginas a los precedentes yámbicos del léxico cómico obsceno y escatológico, y a otras diversas reminiscencias ${ }^{5}$, poniendo de relieve su importancia para comprender la presencia de dichos elementos en la comedia. Pero, como intentaremos demostrar a continuación, no son esos campos semánticos los únicos que permiten relacionar el léxico yámbico y el cómico.

Si bien no es correcto definir la lengua artistofánica sin más como «coloquial», no hay dudas sin embargo sobre la presencia de este nivel de lo cotidiano como constituyente sustancial de su lenguaje y, sobre todo, como rasgo distintivo frente a características más o menos compartidas con otros géneros. Es igualmente patente que al hablar de esos niveles de «Umgangsprache» 0 , más aún, de lo familiar o vulgar, no podemos quedarnos en los campos semánticos de la sexualidad o de lo excrementicio y que, además, hemos de presentar, para tratar de caracterizar ese lenguaje o estilo, una serie amplia de rasgos que afectan no sólo a la palabra aislada, sino también a locuciones enteras o a la sintaxis.

Se trata, por tanto, de ver si esos aspectos eran localizables también en la lengua del yambo. Pero no sólo los referentes al lenguaje, sino también los de estructura, contenido, temática, etc. La lectura detenida de los

\footnotetext{
3 Aunque no falten apreciaciones aisladas en obras recientes. Así, C. Miralles y J. Pòrtulas, al referirse al componente dramático y mimético en Arquiloco e Hiponacte, han señalado que «los lazos entre el yambo y la comedia ática pueden adquirir una nueva dimensión si se analizan desde otra perspectiva" (Archilochus and the Iambic Poetry, Roma 1983, p. 111). La relación de paralelos cómicos con los fragmentos de Hiponacte aportada de forma exhaustiva por E. Degani en la edición arriba citada (en adelante $e d$.) habla por si sola.

4 The Maculate Muse. Obscene Language in Attic Comedy, New Haven/Londres 1975.

'Cf. especialmente p. 19 ss.
} 
yambógrafos muestra a nuestro juicio, a Hiponacte como el más próximo a las características de la comedia, siempre dentro de la prudencia que cualquier afirmación de este tipo exige al tratar de autores de los que tan escasos textos conservamos y en tan mal estado. El otro autor utilizable para un cotejo similar, Arquíloco ${ }^{6}$, posee algunas características en conjunto que lo hacen menos apropiado para poder ver con detalle el hilo conductor de uno a otro género, sobre todo por su mayor proximidad al lenguaje épico, como ya demostró D. Page en un trabajo fundamental?

2. Veremos en primer lugar aquellos rasgos del lenguaje que permiten apreciar la proximidad a las características de la comedia ática.

2.1. Compuestos. Ante todo encontramos en Hiponacte algunos compuestos que, tanto por su formación como por su contenido, merecían haber sido extraídos de cualquier comedia. En la lista recogida aparecen dos que hay que considerar dudosos, aunque por razones diferentes:

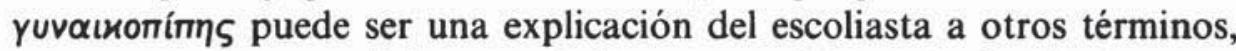
aunque en algunas ediciones se incluye como hiponacteo ${ }^{8}$, mientras que sobre $\sigma \pi о \delta \eta \sigma \iota \lambda \alpha u ́ \rho \alpha$ («pulverizadora de calles», es decir, "prostituta». También podría traducirse como "pulverizadora de cloacas») ${ }^{9}$ existen dudas sobre si debe atribuirse a Hiponacte (135d) o estamos ante el fragmento de un cómico (1352 K.), vacilación esta última que no hace sino abundar en la idea sostenida, hasta el punto de ser admisible en cualquiera de

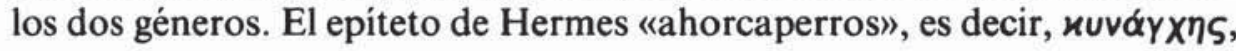

\footnotetext{
- Semónides resultaba excesivamente limitado en cuanto a contenidos; en cualquier caso, la "dramatización" que se observa en algunos de los fragmentos hiponacteos es difícilmente localizable en los otros yambógrafos y constituye sin duda una de las claves de su éxito entre los seguidores tardíos del género, como Fénix de Colofón o Herodas.

7 "Archilochus and the Oral Tradition», Archiloque, Entretiens Hardt X, Vandoeuvres/Ginebra 1963, pp. 119-179. Sobre proximidad a la composición oral y las características de la técnica arquiloquea puede verse también la obra de $\mathrm{A}$. Aloni, Le Muse di Archiloco. Ricerche sullo stile archilocheo, Copenhague 1981.

8 Asi $\mathrm{O}$. Masson, Les Fragments du poète Hipponax. Edition critque et commentée, Paris 1962, fr. 118,16.

9 Ésta es una traducción del término meramente conjetural, siguiendo una tradición quizá un tanto puritana. El otro extremo lo constituye el «trituracoños» de F.R. Adrados, Elegíacos y yambógrafos arcaicos, II, Madrid $1981_{2}$, p. 315 , aclarando (n. 10) que «está referido a una mujer», lo que no sería extraño en el conjunto del lenguaje metafórico obsceno de los yambógrafos; $\sigma \pi 0 \delta \varepsilon \omega$ equivale a $\beta \iota v \varepsilon \hat{\omega}$ en Aristófanes (As. $942,1016)$ y M.L. West lo conjetura con el mismo sentido para el fr. 104,15. Lo que no está tan claro es si $\lambda \alpha u ́ p \eta$ ha de entenderse entonces como "calle» o «cloaca» equivaliendo a "coño»..
} 
parece creación hiponactea para traducir el lidio $K \alpha v \delta \alpha u ́ \lambda \eta \varsigma^{10}$; en todo caso, es formación más acorde con la composición nominal griega, según la interpretación que hoy en dia se da a la voz lidia, que el tardío oxuגo-

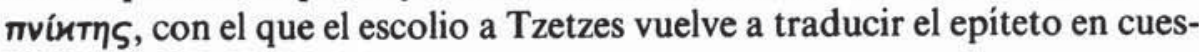
tión ${ }^{11}$.

Algunos de los compuestos bimembres basan su uis comica en la ironía

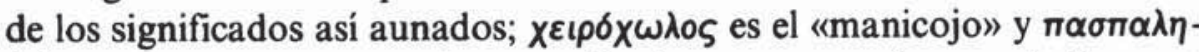
$\phi \alpha ́$ yos, que parece ser encierra un término poco común para indicar un

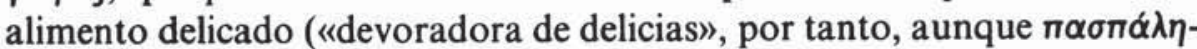
también puede entenderse como «mijo») se aplica por añadidura a una gorrina. Pero mucho más próximos a la comedia están los que aún quedan por comentar: por un lado поvтох $\alpha \rho u \beta \delta ı \varsigma$, que, si bien según Masson $^{12}$, quien sigue a E. Risch ${ }^{13}$, debería traducirse como "esta Caribdis que se tragaría el marn, deben tenerse en cuenta las observaciones de $\mathrm{E}$. Degani ${ }^{14}$ en el sentido de que estemos ante una definición de las «tragaderas oceánicas» del personaje atacado en el fragmento (Eurimedontiades) y no ante un epiteto del mismo, con lo que se resuelve el dilema del género

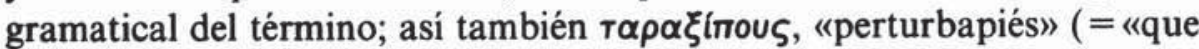
hace caer o resbalar»), que probablemente parodia un epiteto de Posidón, $\tau \alpha \rho \alpha \xi$ เmmoร; o algunos compuestos de carácter obsceno, como $\beta \alpha \sigma \alpha \gamma \iota x \delta$ pos (quizá con elemento léxico no griego), que encontramos explicado

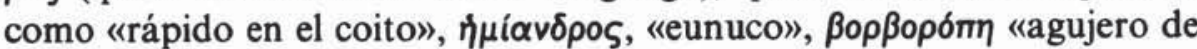
barro», referido al sexo de la mujer, y иuбoxи́v "anoabierto». Por otro lado están aquellos que surgen de la unión de más de dos elementos, ya

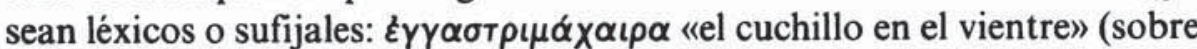
el que volvemos a traer a colación las observaciones de E. Degani ${ }^{15}$, para-

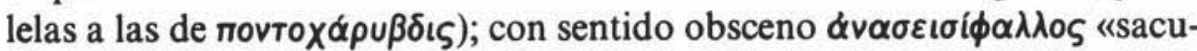

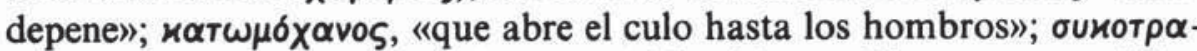

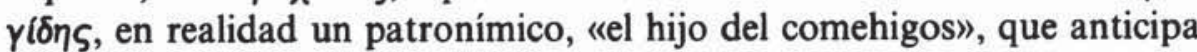
el abuso cómico tan frecuente en Aristófanes de este sufijo, - $-\delta\lceil\eta \varsigma$, que siempre ha conservado una connotación de nobleza ${ }^{16}$; el exhibicionismo

10 Cf. L.R. Palmer, The Greek Language, Londres/Boston 1980, p. 113.

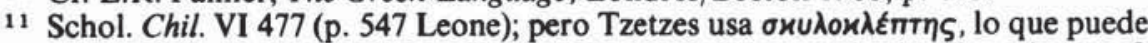
suponer una interpretación muy diversa del término («el que roba los despojos»): cf. A.R. Burn, The Lyric Age of Greece, Londres 1978, p. 102.

12 P. 169.

13 IF 59, 1944-49, pp. 27 y 277, con más ejemplos cómicos.

14 Art. cit. supra, p. 150 ss.

15 Ibidem, p. 149 ss.

16 Cf. E. Fraenkel, «Namenwesen», RE XVI 2, 1935, cols. 1611-1670 (vid. col. 1631, Il. 23-26); Ch. Frei-Lüthy, Der Einfluss der griechischen Personennamen auf die Wortbildung, Heidelberg 1978, p. 51. 


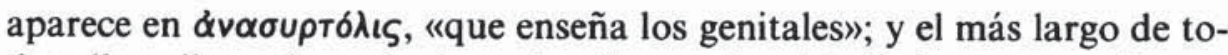
dos ellos, digno de cualquier animado pasaje aristofánico, $\mu \varepsilon \sigma \sigma \eta \gamma u \delta о \rho \pi o-$ $\chi \varepsilon \varepsilon \sigma \tau \eta$, «el cagón a media cena», nos remite al terreno escatológico ${ }^{17}$.

2.2. Lenguaje obsceno (sexo y escatología). Varios de los compuestos que acabamos de enumerar nos han introducido, casi violentamente, en los campos semánticos más generosamente atestiguados en el yambo y en la comedia, como son los del sexo y la escatología. Como ya hemos indicado anteriormente, es el ámbito léxico mejor conocido y, sobre todo desde el libro de J. Henderson, perfectamente clasificado según los significados. Por ello no vamos a insistir en este aspecto, aunque resumiremos, basándonos en dicho libro, los datos que se refieren a Hiponacte. Nos encontramos, en efecto, en sus fragmentos un número elevado de términos que se incluyen en las significaciones antedichas y que, como en el caso de la comedia, suelen ser vocablos utilizados humorísticamente en sentido figurado. Así, para los genitales masculinos aparecen términos propios, como $\delta \rho \chi\llcorner\varsigma$ о $\phi \dot{\alpha} \lambda \eta \eta$, pero también otros metafóricos, como $\alpha \lambda \lambda \tilde{\alpha} \varsigma$, «sal-

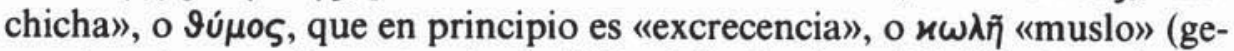
neralmente "pernil» o «jamón»), dicho del miembro viril. Mucho más variada, igual que ocurre en la comedia, es la designación del órgano

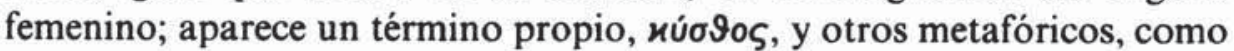

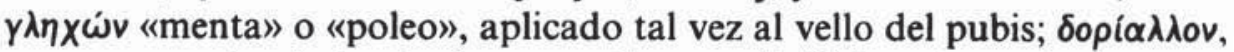

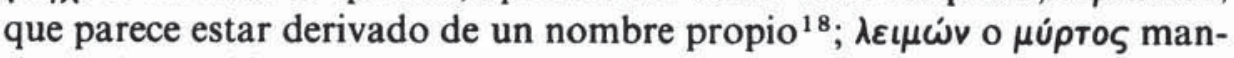
tienen la metáfora vegetal; no falta el higo, lox $\alpha \varsigma$ y, del mundo animal,

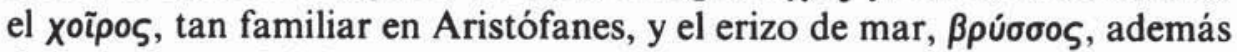

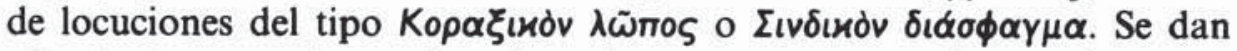
además las menciones de otros órganos, como nuбós, aquí "ano",

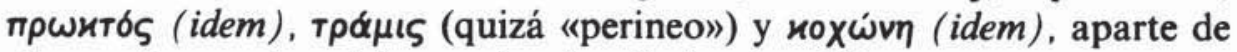
algunos juegos de palabras sobre la raiz de $\pi u ́ \gamma o \varsigma^{19}$.

Junto a ellos, otros términos nos remiten a una variada gama de actos sexuales, en un conjunto que haría las delicias de los aficionados al género erótico. Téngase en cuenta que algunos pasajes están por entero dedica-

17 «Bel exemple de composé péjoratif, comparable à ceux que forgeront plus tard en grand nombre les comiques" (Masson, op. cit., p. 158, remitiendo a E. Fraenkel, Geschichte der griechischen Nomina agentis, I, 1910, p. 235).

18 No compartimos la opinión de W. de Sousa Medeiros (Hipónax de Éfeso, I. Fragmentos dos Iambos, Coimbra 1961, p. 130), quien pretende ver en $\gamma \lambda \eta \chi \omega \dot{v}$ un afrodisiaco y no una metáfora obscena. Los paralelos aristofánicos (cf. "Indice" al final del presente artículo) nos parecen muy reveladores. Para $\delta o p i \alpha \lambda \lambda$ ov cf. P. Chantraine DELG, s. u.

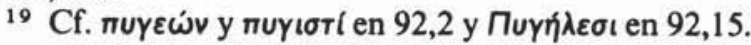


dos a la descripción de tales menesteres ${ }^{20}$. El coito se define con el verbo

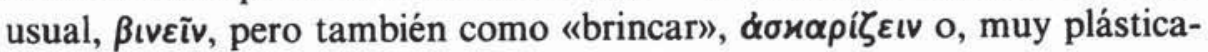

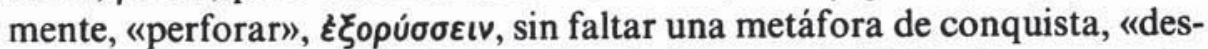
pojar de las armas», $\sigma \varkappa u \lambda \varepsilon u ́ \varepsilon เ v$. La alusión a actividades homosexuales queda reflejada en algunos pasajes, no sin cierta exageración a veces: en el fragmento 41 el hablante teme que le dejen tan agujereado como la madera de higuera ${ }^{21} ; \mathrm{y}$, junto a los compuestos citados arriba, contamos con

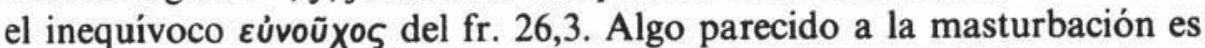

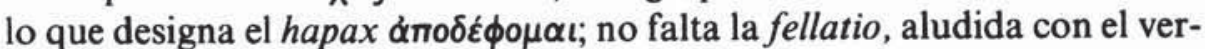

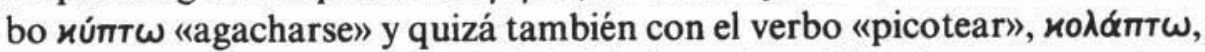
aparte de que puede ser la habilidad de la mujer calificada como $\mu v \sigma \alpha ́ \alpha v \eta$ en el fr. 105,10; y la descripción del cunilingus parece deducirse del fr. 124 («sorber el higo de Lébedo»). Por último, en cuanto a lo escatológico, destaca la recurrencia del verbo $\alpha v \alpha \tau \iota \lambda \tilde{\alpha} v$, «tener diarrea», y de $\delta \mu \varepsilon i ́ \chi \varepsilon \iota v$ «orinar»; y encontramos asimismo los sustantivos que designan la "boñiga",

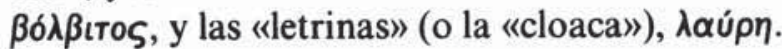

2.3. Todo el léxico presentado hasta el momento constituye sin duda un conjunto capaz de convencer al más escéptico respecto al parentesco por ascendencia o anticipación de este lenguaje con el de la comedia ática. Pero si detuviéramos aquí la exposición habríamos dicho muy poco y, sobre todo, no habríamos aportado apenas nada a lo ya conocido. En efecto, en cualquier comedia ática, junto al variado vocabulario de tipo obsceno, se observa la presencia de un nivel de lengua que, sin llegar a tener necesariamente ese valor, nos permite calificar al léxico que lo constituye de familiar, coloquial o, en un sentido amplio, vulgar. En consecuencia, es procedente preguntarse por la existencia de un léxico semejante, incluso idéntico, en la lengua de Hiponacte, que confirme en este aspecto el «preludio" de la comedia que se postula para el yambo arcaico y que estamos ahora materializando en Hiponacte. Si admitimos la relación entre el contexto social y la forma en que el «mensaje» se materializa en ese contexto, tendremos que buscar en Hiponacte la prueba de que tal principio se cumple. Si la presencia del lenguaje obsceno tiene un fundamento sobradamente reconocido en unos orígenes rituales muy concretos del género, lo cual ya es en cierto modo partir de una explicación sociológica de tal presencia, del mismo modo podemos relacionar la existencia de niveles coti-

20 Vid. frs. 104,34; 119, 135, 155 a-c, 160, 182.

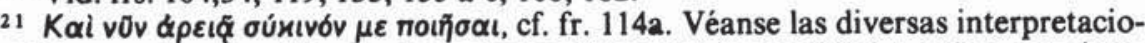
nes del fragmento resumidas en el apartado crítico de E. Degani (ed.), quien, por cierto

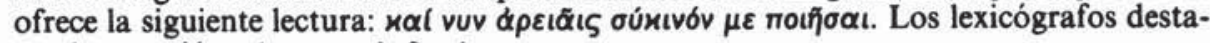

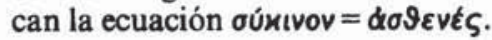


dianos de lengua tanto con esos mismos orígenes, en un sentido más amplio, como con la persistencia de unas condiciones y un entorno social que contribuyen al mantenimiento de esos niveles acompañando a su desarrollo.

Pues bien, estos postulados se confirman plenamente en un análisis detallado del léxico hiponacteo. En éste se distingue un vocabulario coloquial más o menos común con otras épocas de la historia de la lengua griega y con otros dialectos y ámbitos territoriales de Grecia, con notables coincidencias en la comedia ática. En segundo lugar aparece un vocabulario que parece más o menos asignable al ámbito jonio, aunque existen dudas en algunos casos concretos. Y, en tercer lugar, un conjunto de «barbarismos» que indudablemente, junto con las anteriores clasificaciones, contribuyen al sabor local-popular del conjunto, ya que probablemente su presencia se explica por ser términos familiares al auditorio de estas composiciones $^{22}$. Junto a esta triple clasificación nos ha parecido oportuno establecer dos grupos aparte con palabras correspondientes a un vocabulario concreto, por tanto también susceptible de definirse como cotidiano, como es el del ámbito culinario y los términos zoológicos. A ningún lector de Aristófanes le resultará extraña la presencia de ambos.

Ahora bien, antes de describir con detalle estos grupos conviene dedicar unas líneas a un problema fundamental de la lengua hiponactea; es éste el de la naturaleza de los fragmentos conservados, que llevaron a G. Pasquali a dar a nuestro autor el calificativo de "poeta glosemático»" ${ }^{23}$. Es claro que todo reproche debe dirigirse a la tradición a la que, como tantas veces ocurre en las literaturas clásicas, le debemos al mismo tiempo la conservación de unos textos y la naturaleza discutible de muchos de ellos, con una selección excesivamente orientada a un interés muy concreto. Pero el mero hecho de que el léxico hiponacteo fuera ya objeto de curiosidad en la Antigüedad es suficientemente significativo. Se trataba de un código lingüístico sumamente peculiar, que no podía por menos de atraer la atención de los lexicógrafos antiguos, prestos a la caza de cualquier alteración de la norma lingüística al uso, cuando la "normalización» del griego había supuesto ya la renuncia a numerosas y ricas peculiaridades. Pero esto no debe hacernos cometer un error de perspectiva: el aparente exotismo es un espejismo sin fundamento. El hecho real es que lo más puramente jonio es también lenguaje familiar y popular, y los términos no helénicos de este lenguaje ni son tantos como a veces se ha pretendido ni son elementos mal integrados, sino todo lo contrario; hay que ver

${ }^{23}$ SIFC 7, 1929, p. 311 (citado por Masson, op. cit., p. 21). 
en Hiponacte «un poeta griego que se ha permitido a veces emplear palabras extranjeras más o menos aclimatadas en suelo jonio en el siglo $\mathbf{v i}^{24}$.

\subsubsection{Léxico popular no necesariamente jonio.}

Verbos: Tanto desde el punto de vista del significante como del significado nos encontramos con un buen número de verbos que nos sitúan en un nivel de lengua cotidiano y familiar. Así, se dan bastantes con valor onomatopéyico, formados en su mayoría mediante reduplicación expresiva de la raíz: $\beta \alpha \mu \beta \alpha \lambda u ́ \zeta \omega$ «balbucear» (y «rechinar los dientes»); $\beta \alpha \tau T \alpha-$ $\rho i \zeta \omega$ «idem»; $\beta 0 \rho \beta o \rho u ́ \zeta \omega$ «hacer gorgoteos»; $\varepsilon \mu \beta \alpha \beta \alpha \zeta \zeta \omega$ «balbucear», pero quizá más bien «interrumpir (con ruidos)» ${ }^{25}$; o $\mu$ oı $\mu$ ú $\lambda \lambda \omega$ (sobre la raíz de $\mu u ́ \lambda \eta$ y que puede considerarse también metáfora obscena) ${ }^{26}$. Onomatopéyicos, aunque no con la misma formación de los precedentes, son

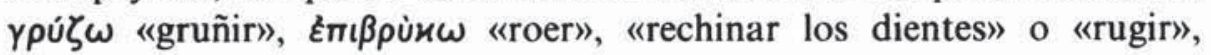

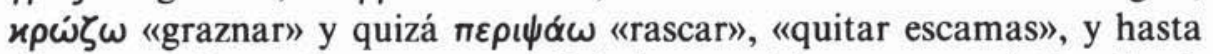

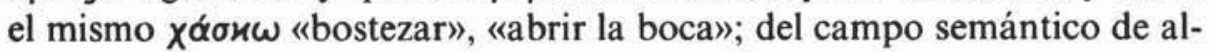
gunos de los reduplicados ya vistos puede citarse $\varkappa \omega т i \lambda \lambda \omega$ "parlotear». Pueden incluirse también verbos que describen determinados movimientos del cuerpo: $\alpha \rho \rho \iota \chi \alpha \dot{\alpha} \mu \alpha \iota$ «trepar», $и \alpha т \alpha \pi \lambda i \sigma \sigma \omega$ «poner la zancadilla»;

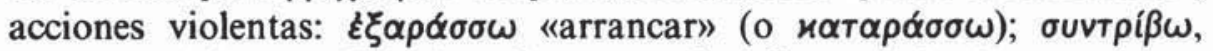

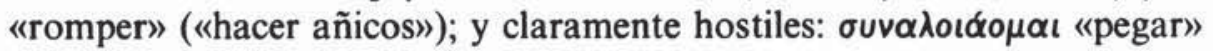
(lit. «trillar la cara a uno»). Claramente coloquial es $\beta \rho \varepsilon v \vartheta u ́ o \mu \alpha \iota$ «pavo-

${ }^{24}$ Masson, op. cit. p. 32. La formulación es algo simple, aunque no incierta. La complejidad del problema del contacto cultural y lingüistico ha sidoanalizada con detalle por G. Tedeschi, «Lingue e culture in contatto: il problema della lingua in Ipponatte", Incontri Linguistici 4, 1978, pp. 225-233; "I prestiti linguistici nei frammenti ipponattei e il problema dell'interferenza culturale ad Efeso", $Q F C$ 3, 1981, pp. 35-48. Para F. R. Adrados, "Sociolingüística y Griego antiguo", $R E L 11,2$, 1981, pp. 311329 , Hiponacte "resulta francamente vulgar» y sería el único caso de tal nivel de lengua en la poesía arcaica y clásica, mientras que el resto de los yambógrafos y Aristófanes se quedan en el nivel "popular» (p. 316). Compartimos las diferencias entre, por ejemplo, un Arquíloco y un Hiponacte, pero no la distinción de "vulgaridad» que se aplica a Hiponacte (por oposición a un nivel "popular»), a quien, como defendemos en este trabajo, vemos más próximo a Aristófanes. Tal vez la naturaleza de los fragmentos pueda apoyar tal clasificación, pero también es verdad que es más culto de lo que parece. El fr. 128, que da pie al trabajo de E. Degani aqui elogiado (cf. nota inicial) debe prevenir al respecto y también poner en guardia frente a las distinciones entre lo «literario" y lo "popular".

${ }_{25}$ Se ha supuesto un origen lidio, al menos para el simple $\beta \alpha \beta \alpha \zeta \omega$; cf. K. Latte en su edición de Hesiquio, s.u., y G. Neumann, Untersuchungen zum Weiterleben hethitischen und luwischen Sprachgutes in hellenistischer und römischer Zeit, Wiesbaden 1961, p. 57; $\beta \alpha \beta \alpha \zeta$ aparece en Arquíloco, fr. 297.

${ }_{26}$ Para unos el «higo de Lébedo", objeto de la acción verbal, es el miembro viril (así A. Bartalucci, «Hipponacteae interpretatiunculae», Maia 16, 1964, p. 245); para otros, el sexo de la mujer (Henderson, op. cit., p. 22). 
nearse» (seguramente metafórico a partir de $\beta \rho \varepsilon ́ v \vartheta ० \varsigma$, nombre de un ave),

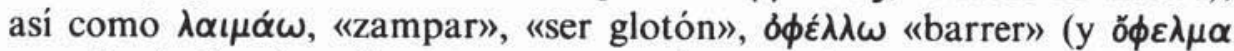
"escoba»), término obsoleto que se verá superado por $\sigma \alpha i p \omega ; \dot{\alpha} \lambda \phi \imath \varepsilon \varepsilon u ́ \omega$ es «ir a la molienda (de cebada)»; $\sigma \varkappa \alpha \pi \alpha \rho \delta \varepsilon u ́ \omega$ «socorrer», «echar una mano" es muy probable que no sea un préstamo, como han supuesto al-

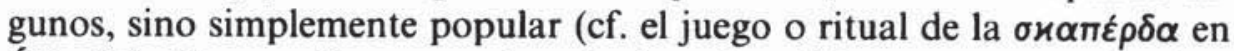

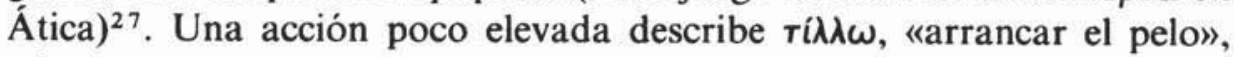
mientras que $\tau \rho \omega ́ \omega \omega$ mantiene sin duda su sentido originario (es decir, aún funciona metafóricamente) de "roer», de modo que, respecto a los formados sobre $\varepsilon \delta$ - o $\phi \alpha \gamma$ - mantiene una relación parecida a la del español «tragar» ( $\tau \rho \omega \gamma-/ \tau \rho \alpha \gamma-)$ frente a "comer»; en este campo semántico

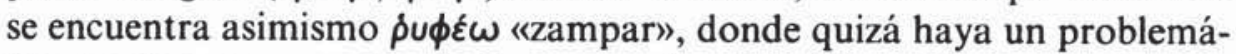
tico grado cero respecto a la forma usual en ático ${ }^{28} ; \mu \alpha \delta \alpha \omega$ es propiamente un término casi ténico, «humedecer», «impregnar» (atestiguado en $\mathrm{Hi}$ pócrates), pero no puede descartarse un uso metafórico ${ }^{29}$.

Sustantivos: En la descripción de cualquier actividad, el poeta yámbico nos acercará con su lenguaje a la realidad, a lo tangible. Las escenas que se configuran en los fragmentos de Hiponacte, sobre las que volveremos más adelante, tienen ya una gran proximidad con situaciones similares de la comedia. Es normal la aparición del vocabulario concreto, con menciones de objetos de uso cotidiano, como las prendas de vestir, según se enumeran en el célebre fragmento "petitorio" n. ${ }^{\circ} 32$. $\Sigma i \phi \omega v$ es una "caña» o "tubo" utilizado para beber o extraer líquidos ${ }^{30} ; \mu \alpha \rho i \lambda \eta$ es la «brasa»; $\mu \cup \lambda \alpha$ หpí una "rótula», aunque también se ha pensado en un in-

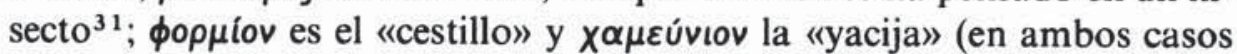
con la aparición del diminutivo). Pedestre es asimismo la mención del

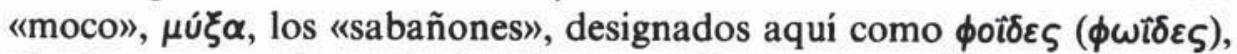
término que propiamente significa "ampolla» o «quemadura», o como $\chi^{i}$ -

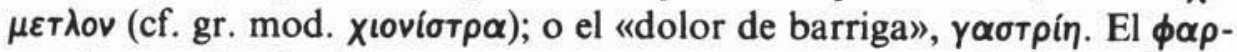
$\mu \alpha \varkappa \delta ́ \varsigma$, nombrado siete veces, nos pone en contacto con ritos populares, lo mismo que la $\varkappa \rho \alpha ́ \delta \eta$, «rama (de higuera)». El instrumento para barrer

27 Cf. Chantraine, DELG, s.u., y Masson, op. cit., p. 124.

28 Aunque Focio (Lex. II, 137 Naber) lo da como propio de Hiponacte, es muy probable que se deba al vocalismo. De hecho, $\rho \circ \phi \varepsilon \omega$ es frecuente en Aristófanes; véase el comentario de A.C. Cassio, Aristofane, Banchettanti ( $\triangle A \mid T A \backslash H \Sigma)$. I Frammenti, Pisa 1977 , p. 53 (fr. $6=203$ K.).

29 Se da el caso de que en a.i. mádati (procedente de la misma raíz) es «estar ebrio». De todas formas, carecemos de contexto suficiente; cf. бanpós.

30 Aunque también es el nombre de un tipo de hormiga; cf. L. Gil, Nombres de insectos en griego antiguo, Madrid 1959, p. 37.

31 Concretamente una especie de saltamontes; cf. L. Gil, op. cit., p. 169 s. 
es $\delta \phi \varepsilon \lambda \mu \alpha$ y el montón de tierra que se acumula $\sigma \alpha \rho \mu \delta ́ \varsigma$. No falta la presencia del ladrón, $\phi i \lambda \eta ́ r \eta \varsigma$ (ya en Hesíodo) y $\phi \tilde{\omega} \rho$. En el vocabulario abstracto hay términos casi de "argot", como oxip $\alpha \phi_{\circ}$, "truco", derivado del léxico del juego.

Algunos sustantivos se usan en sentido traslaticio o metonímico: al

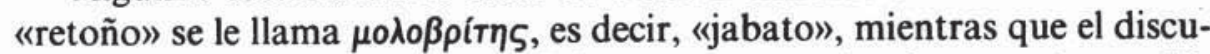
tido término бко́тоৎ parece definir a un personaje alto «tenebroso" ${ }^{32}$;

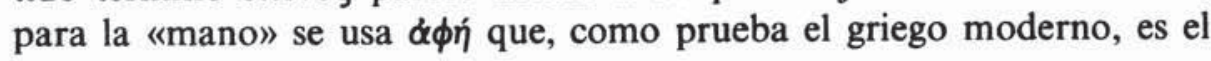
«toque».

Adjetivos: En su forma simple son escasos, aunque alguno de ellos es

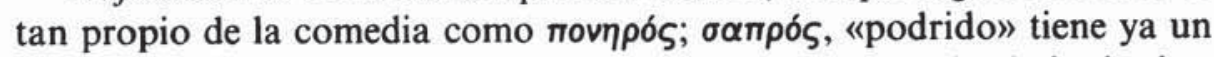
valor más técnico, aunque deben tenerse en cuenta las salvedades hechas a propósito de $\mu \alpha \delta \alpha \dot{\omega} \omega ;$; $\cup \rho$ тоৎ plantea un problema: la acentuación oxítona es la de un adjetivo, "curvo", mientras que la acentuación paroxítona es la de un sustantivo que viene a significar "red», «tamiz» o incluso «jau-

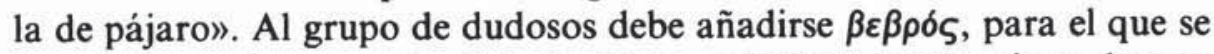
han dado versiones contradictorias ${ }^{33}$. Lo más importante, sin embargo, es el dato de que la mayoría de los adjetivos se incluyen en los grupos antes estudiados, abundando la forma de compuesto y el sentido obsceno.

2.3.2. Léxico familiar de posible origen jonio. Como mera hipótesis, tan sólo en algunos casos confirmada por los lexicógrafos y autores que transmiten los fragmentos, puede apuntarse la posibilidad de que algunos términos de uso común sean más propios del léxico jonio, de lo que podría ser un indicio la coincidencia de su aparición en Hiponacte, Heródoto, Hipócrates, etc. Tal es el caso de algunos verbos y sustantivos, en parte ya incluidos entre los términos coloquiales. Así el expresivo $\pi \alpha \mu$ $\phi \alpha \lambda \alpha \dot{\omega} \omega$, «mirar con los ojos bien abiertos»; $\beta \alpha \pi i \zeta \omega$ «abofetear» (aún en griego moderno); quizá deban mencionarse aquí de nuevo $\delta \phi \varepsilon \lambda \lambda \omega \omega$ «barrer» y $\lambda \alpha \sigma \vartheta \alpha i v \omega$ «burlarse», «injuriar». Entre los sustantivos puede seña-

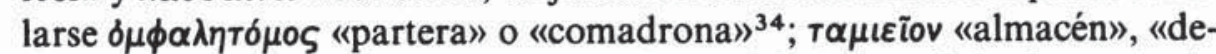
pósito" (aunque parece común al jónico-ático) y quizá el ya citado

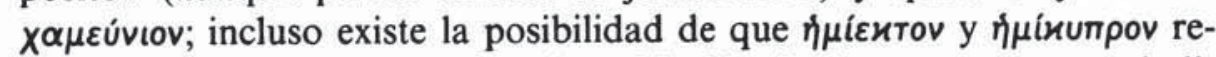
presenten medidas de uso normal en el ámbito jonio, aunque esto no indiloc.).

32 "'Tenebrio', i.e., qui in tenebris fraudolenta foedaque agitat» (E. Degani, ed. ad

${ }_{33}$ Remitimos una vez más a E. Degani, ed. ad loc., para un resumen de estas interpretaciones que oscilan entre su consideración o no como préstamo y su utilización in bonam o in malam partem.

34 Cf. Masson, op. cit., p. 116; el término aparece en Hipócrates (Mul. I 46). 


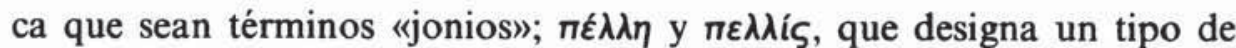
copa o vaso, podría ser también de uso normal en Jonia. Entre los a d je-

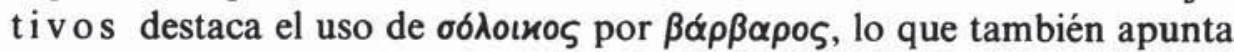
a un ámbito geográfico concreto. En fragmento espurio se transmite el oscuro $\chi \lambda$ Aoúvns, ya atestiguado en Homero $^{35}$, que podría representar una supervivencia popular en el ámbito jonio, aunque después se encuentre en autores representantes de otros dialectos y géneros; su sentido parece ser el de «afeminado», "castrado».

2.3.3. Préstamos léxicos. Entre los «barbarismos» que se dan en Hiponacte predominan también sustantivos de tipo concreto que designan objetos de uso común. Aparecen aquí prendas de vestir o calzado, como

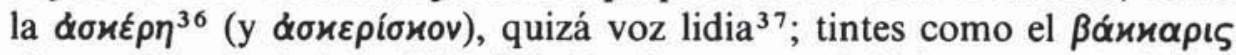
«bermellón", quizá también lidio ${ }^{38}$; alimentos o bebidas como el célebre

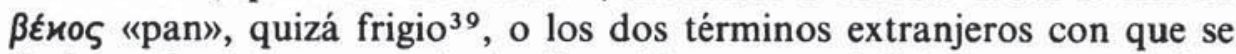
designa al "vino», uno egipcio, ह̌ $\rho \pi \varsigma^{40}$, y otro quizá de sustrato medite-

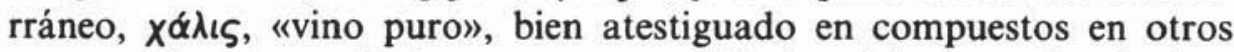
autores. De origen egipcio parece ser también la palabra para la «tinaja»,

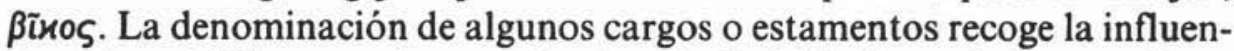
cia cultural lidia, pues éste es el origen indudable de xaúns "sacerdote"

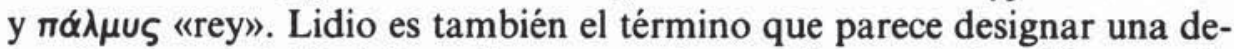
terminada colctividad femenina con carácter religioso, סoũ $\mu \circ \varsigma^{41}$; no es de extrañar que, como หaúns, penetre en el ámbito popular, en que las manifestaciones religiosas suponen la ocasión más importante de actividad común y relación social más plena. Menos aún sorprenderá la aparición de $\mu \alpha u \lambda ı \sigma r i ́ p ı v$, término para el que las opciones varían desde una «moneda" al "burdel», aunque su origen lidio (para lo que, por otra parte, no

3s Il. IX 539. Sorprende el escolio B al verso en cuestión con su indicación de que el término se usaba en alguna comunidad doria con el sentido de $\alpha \phi \rho, \sigma r i \xi s, ~ " q u e ~ e c h a$ espuma». De cualquier forma, la autoría del fragmento es muy dudosa.

36 Aparece en una inscripción ática: cf. $S E G$ 13, 1956, n. ${ }^{\circ} 148$.

37 Cf. Masson, op. cit., p. 125.

38 Cf. Masson, op. cit., p. 135.

$39 \mathrm{Cf}$. Hdt., II 2.

40 Cf. Masson, op. cit., p. 148.

41 Este discutido término, que algunos han querido sustituir por $\delta \circ \tilde{\lambda} \lambda$ os, , reaparece en algunos otros lugares no menos problemáticos (A.P. VII 222,3 [Filodemo]; $C I G$ 3439 [Lidia, s. III d.C.]). Acerca del posible origen frigio del término cf. A. Heubeck, Lydiaka. Untersuchungen zu Schrift, Sprache und Götternamen der Lyder, Erlangen 1959 , p. 81, n. 2. Véase una defensa reciente del carácter de tíaso femenino en C. Calame, Les choeurs de jeunes filles en Grèce archaïque, Roma 1977, I, p. 365 ss. 
sería un obstáculo su sufijación típica griega) es algo dudoso ${ }^{42}$. Nqvíatov parece designar un aire de flauta frigio. No faltan insultos de origen ex-

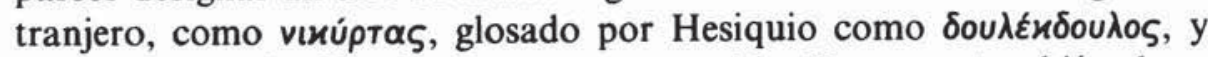
$\sigma \alpha ́ \beta \alpha v v \iota$, cuyo significado cierto no es conocido. Oscuro es también el valor de naũvı, ya que, según Hesiquio, puede ser "pequeño", "grande» o «bueno".

La lengua lidia no aparece atestiguada sólo por sustantivos o adjetivos, sino incluso por formas verbales, como al comienzo del fr. 92, en que

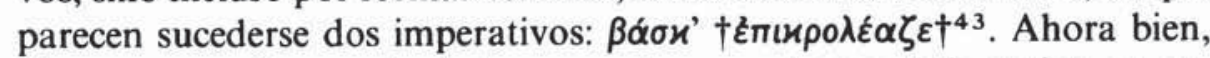
el uso en este fragmento de las expresiones en lengua lidia reviste un carácter muy diferente del de los anteriores, ya que ahora no se trata del uso por el poeta de palabras que ya podían estar integradas en el habla coloquial de la región, sino que conscientemente se hace aparecer a un personaje, una mujer lidia, en cuya boca se ponen esas expresiones, acla-

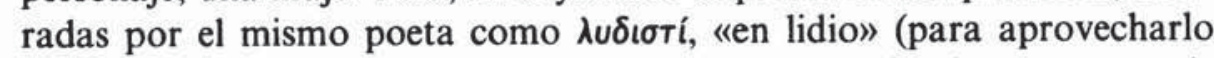
además en un juego de palabras, mediante la creación de nuүıбтi, etc.). Es decir, hay un efecto cómico intencionado, al que contribuye la inclusión de esas palabras en lidio, de modo muy similar al seguido por Aristófanes cuando en algunas escenas hace intervenir a extranjeros o hablantes de diversos dialectos griegos, parodiando su lengua o manera de hablar; y debe tenerse en cuenta la posibilidad de que, cuando en otros pasajes aparecen términos extranjeros, no esté injustificado suponer cierto efecto cómico ${ }^{44}$. Por último, mencionemos los términos $\alpha \lambda i \beta \alpha \varsigma$, «vinagre», a veces considerado como préstamo $0^{45}$, y $\alpha \beta \delta \eta$, de supuesto origen «pregriego». loc.

42 Cf. Masson, op. cit. p. 178 s., y abundantes referencias en E. Degani, ed. ad

${ }_{43}$ Las lecturas son muy dudosas y el pasaje discutido ya desde su hallazgo. Véanse, a modo de ejemplo, las sugerencias de B. Lavagnini, Da Mimnermo a Callimaco. Contributi esegetici e critici ai lirici Greci, Turin 1949, p. 56 ss.; M.L. West, Studies in Greek Elegy and Iambus, Berlin/Nueva York 1974, p. 144 s.

44 Es decir, es muy distinta la parodia de un individuo no greco-parlante de lo que es el uso de términos «indígenas» que pueden estar perfectamente asimilados; aunque con matices y salvando las distancias, no parece fuera de lugar un paralelo de este griego de Asia Menor con el español de América, en cuanto a influjos de lenguas de adstrato, que, en este caso, podria desbordar incluso el mero léxico (cf. V. Rapallo, «Influssi anatolici sulla grammatica di Ipponatte», SIFC 48, 1976, pp. 200-243). En sentido contrario, se ha llegado a utilizar el término "pidgin-Greek" para designar el habla de los vecinos anatolios cuando emplean el griego de estas comunidades (cf. Medeiros, op. cit., p. 22, citando a W.M. Ramsey, Asianic Elements in Greek Civilisation, Londres $1928_{2}$, p. 144).

${ }_{45}$ Cf. DGE, s.u.; el significado en Aristófanes corresponde a una interpretación de su etimologia sobre $\alpha \lambda \varepsilon \dot{\omega} \omega$ y $\beta \alpha i v \omega$ (= «alma en pena»). 
2.3.4. Léxico culinario. $\mathrm{Si}$ a simple vista puede parecer injustificado dedicar un apartado a este grupo léxico, dado que puede considerarse sin valor el que los lexicógrafos nos transmitan con frecuencia nombres de alimentos, un repaso a la poesía griega puede hacer desaparecer pronto esta objeción. La enumeración poética de alimentos es consustancial con la poesía popular, sobre todo en determinadas épocas y sociedades ${ }^{46}$. Aparece, por ejemplo, fuera de los yambógrafos, en un Alcmán ${ }^{47}$, por no hablar, por supuesto, del $\Delta \varepsilon$ ĩnvov $^{48}$ de Filóxeno; y, desde luego, volvemos a encontrar lo mismo en Aristófanes ${ }^{49}$.

El posible valor testimonial de tales enumeraciones desde el punto de vista dietético no es más que relativo, pues su mención puede ser puramente ficticia y responder más a un deseo que a una realidad; pero, viceversa, su aparición no hace más que confirmar su existencia y su conocimiento por el poeta. En este sentido cabe señalar la escasa diferencia entre la enumeración de alimentos aquí recogida y los que aparecen en la comedia, salvo por lo que se refiere a alguna designación concreta. Tampoco faltan utensilios caseros, aunque en número mucho menor, igualmente frecuentes en la escena cómica.

Entre los alimentos tenemos algunos tan comunes como los cereales y sus derivados, como la "cebada" o "harina de cebada", $\langle\lambda \phi \iota r \alpha, x \rho \imath \vartheta \dot{\eta}$;

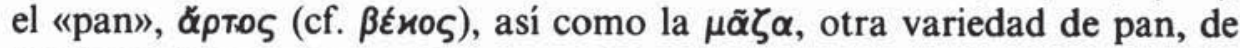
donde podemos pasar a tipos especiales de tortas o pasteles, como los de-

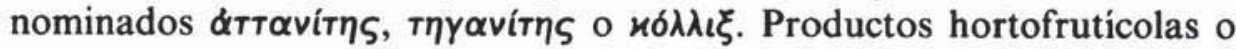

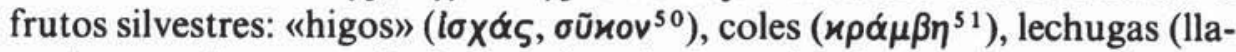

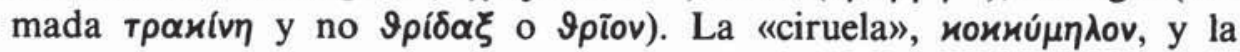

46 No compartimos la valoración que C. Miralles y J. Pòrtulas hacen de este tipo de enumeraciones, al menos plenamente. Para ellos no cabe una consideración realista, sino ritual, pues estariamos ante una reminiscencia de una especie de «trickster" glotón, resucitado y rememorado por el folklore (cf. op. cit., p. 37). El efecto, en nuestra opinión, sobre el auditorio puede ser bastante notable, sobre todo si se quiere contrastar situaciones de riqueza/pobreza. Los propios autores, en apoyo de sus afirmaciones, aducen un fragento como el 124 de Arquíloco, que, sin embargo, es citado por Ateneo (Epitome 7) como censura del poeta a una costumbre de Pericles, comparado con los miconios, quienes, dice, "por su pobreza y por habitar una isla misera, son criticados a causa de su tacañería y de su codicia».

47 Fr. 19 (y cf. frs. 17 y 20) Page.

48 Filóxeno de Léucade, fr. 836 Page.

49 Cf. V. Ehrenberg, The People of Aristophanes, trad. ingl., Londres/Nueva York $19744_{3}$, p. 319 ss. Dentro del lenguaje aristofánico estas enumeraciones se enmarcan en el procedimiento estudiado por E.S. Spyropoulos, L'accumulation verbale chez Aristophane (Recherches sur le style d'Aristophane), Salónica 1974, especialmente p. 86 ss.

50 Contando en estos casos con los normales usos obscenos.

51 Usado en una fórmula de juramento. 


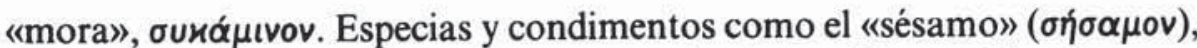

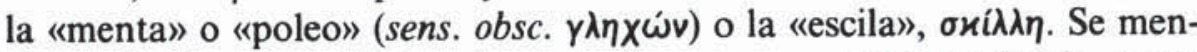

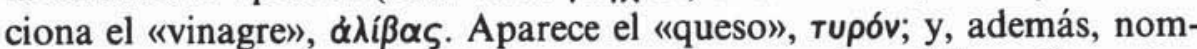
bres de algunos platos especiales, como el $\mu \nu \sigma \sigma \omega t \delta \zeta \varsigma$ o el हैंvo $\varsigma^{52}$, o el ya comentado término $\pi \alpha \sigma \pi \alpha ́ \lambda \eta$ (primer elemento de un compuesto). Entre

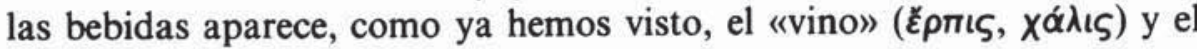
conocido $\varkappa u \varepsilon \varepsilon \dot{\omega} v^{53}$.

Entre los pescados y carnes que se mencionan expresamente como alimentos tenemos la $\vartheta \varepsilon u \tilde{T \iota \varsigma ~ o ~ " c a l a m a r » ~(l a ~} \sigma \eta \pi i ́ \eta$ no parece estar referida

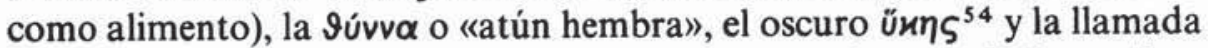

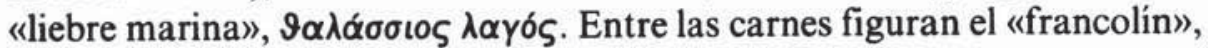

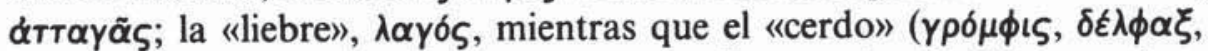

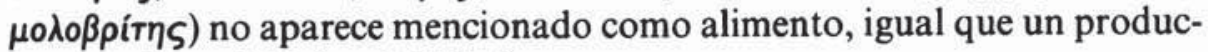
to suyo, la "salchicha» $(\alpha \lambda \lambda \tilde{\alpha} \varsigma)$.

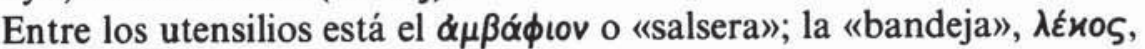

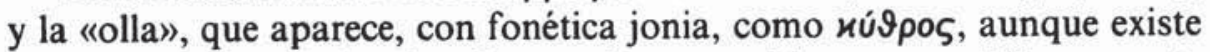

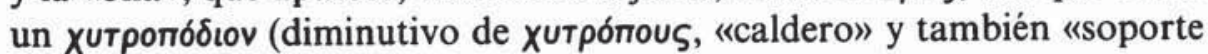
de olla»).

2.3.5. Animales. Aparte de los animales citados en el apartado anterio aparecen mencionados otros muchos, cuya presencia en la transmisión se explica en parte, una vez más, por el interés despertado en los escoliastas y lexicógrafos, pero también por razones que justifican su consideración en este apartado. No es preciso insistir sobre las conocidas tradiciones populares en que encontramos animales bien como protagonistas o bien como términos de referencia en metáforas, símiles, etc. Los yambógrafos son un buen ejemplo para ilustrar esta idea y mucho más un poeta tan directo y plástico como Hiponacte. Pensamos que no en vano la comedia se ha nutrido de tradiciones literarias y festivas con presencia del elemento animal, con resultados tan sorprendentes como los que suponen su recreación y tratamiento por parte de un Aristófanes. Por otro lado, el tomar como referencia insectos, peces, aves, reptiles, felinos, etc., es rasgo común de la lengua popular en cualquier cultura, aparte de aquellos animales que ya han adquirido un carácter modélico respecto de determi-

32 El Étros es una especie de puré que también se encuentra en Aristófanes; el $\mu \nu \sigma \sigma \omega r \delta \zeta$ puede ser el equivalente del muretum, hecho con queso, miel y ajo.

${ }_{53}$ Que ya aparece en Homero, Il. XI 624, etc.

54 Cf. Masson, op. cit., p. 181; Chantraine, DELG, s.u. (quizá la forma del nominativo sea (̋xๆ). 
nadas cualidades (esp.: «es un lince», «es una cotorra», "corre como un galgo").

Entre los insectos no hay constancia clara más que de la "mosca»,

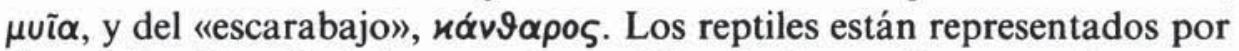

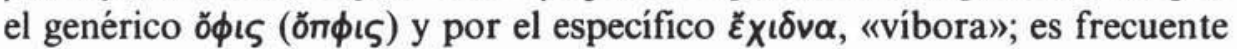
además la mención del «lagarto», bajo las formas ироиó $\lambda \circ \varsigma^{55}$. Una presencia relativamente amplia corresponde a las aves, entre

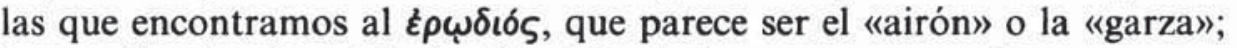
la extraña $\varkappa u ́ \mu \iota v \delta ı \varsigma$, de la familia de las lechuzas, pero que ofrece una problemática identificación ${ }^{56}$. El $\chi \alpha \rho \alpha \delta \rho \iota^{\prime} s$ puede ser el charadrius oedricnemus, es decir, el «alacaraván» o "árdea» ${ }^{57}$. Entre los mamíferos está el

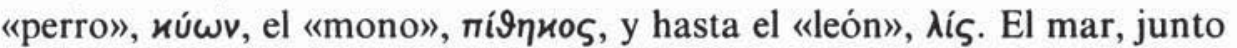
a los pescados antes mencionados, está representado por el "cangrejo»,

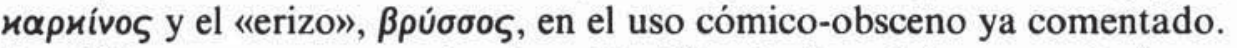
Por último, aparece un animal no identificado, la $\chi \iota \lambda \iota \alpha ́ \alpha \rho \alpha$ o $\chi \iota \lambda \alpha \alpha \dot{\alpha} \gamma \rho \alpha$, quizá relacionado con $\chi \iota \lambda \hat{s} \varsigma$, «pasto».

2.4. Si nos limitáramos sólo al léxico, aislando palabra por palabra, es evidente que no ofreceríamos un panorama completo de lo que constituye el estilo "cómico» de Hiponacte y de las numerosas coincidencias con el lenguaje aristofánico. En Hiponacte a veces no sorprende tanto el uso de una palabra aislada como el contexto en que se incluye. La combinación de los distintos aspectos léxicos antes citados produce un efecto especial, aunque muchas veces (hay que repetirlo) no es posible apreciar esto debido a la transmisión de meras glosas. Pero no sólo la combinación de los elementos antes citados consigue sostener ese nivel de lengua entre cómico y coloquial. Existen procedimientos tan caros a la comedia como el uso de los diminutivos, a veces acumulados, como en el fragmento 32

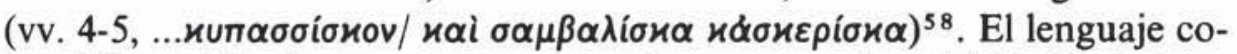
loquial versificado cuenta con expresiones como las del fr. 32 (их́рта

ss Sobre la etimología de este sustantivo véase M. García Teijeiro, «Origen y etimología del nombre 'cocodrilo'», Archivum 25, 1975, pp. 427-444.

$56 \mathrm{Cf}$. W. d'Arcy Thompson, A Glossary of Greek Birds, Londres/Oxford 1936, p. $186 \mathrm{~s}$.; véase además A. Heubeck, Würz. Jahrb. 4, 1949-50, pp. 206-212.

57 Cf. d'Arcy Thompson, op. cit., p. 311 ss.

58 Para la técnica de acumulación de diminutivos y otros sufijos cf. Spyropoulos, op. cit., p. 143 s.; sobre el efecto en Hiponacte, véase la observación de M. García Teijeiro, "Innovaciones sintácticas en la 'koiné'», Unidad y pluralidad en el Mundo Antiguo, Actas del VI Congreso Español de Estudios Clásicos, Madrid 1983, I, pp. 247-277: «Sin duda, Hiponacte imita la manera de hablar de los mendigos profesionales, y consigue así un efecto especial en su parodia» (p. 277). 


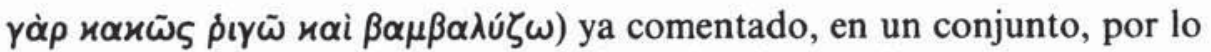
demás, acorde con el tipo de poesía petitoria popular que representa;

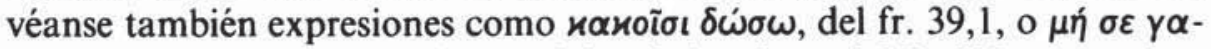
бтрí $\lambda \alpha \dot{\beta} \eta$, «no te vaya a dar un dolor de barriga», del fr. 118.

No menos "cómico" es el uso paródico o fuera de lugar del lenguaje poético, a veces acompañado de un contraste con el nivel de lengua representado por el resto de los elementos léxicos. Así, el uso de un adjetivo

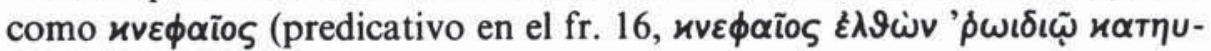
$\lambda i \sigma \vartheta \eta v . .$.$) que también utiliza Aristófanes en los pasajes líricos; y otros$

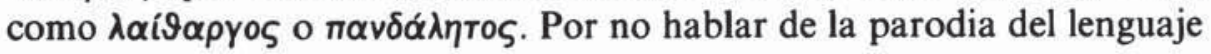
épico que representa el fr. 128 completo (por cierto, uno de los pocos no yámbicos conservados de Hiponacte).

Con frecuencia se reserva para el final de la composición una expresión que ofrece algún contraste con lo precedente, un inesperado toque que destaca bien por su vulgaridad o bien por su violenta irrupción tras una enumeración que no lo hace esperar; es decir, estamos ante una espe-

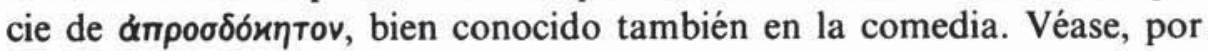

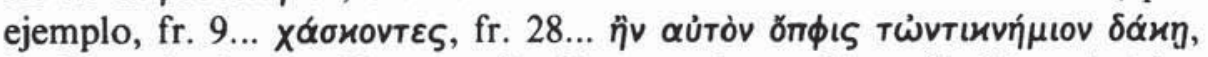

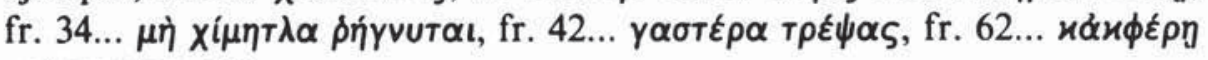

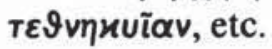

2.5. Nombres "parlantes». Mención especial merece este tema, revitalizado recientemente por M. Grazia Bonnano ${ }^{59}$. Aunque los ejemplos más seguros en Hiponacte no son muchos, sí son suficientes para permitirnos incluir su utilización como uno de los recursos «cómicos» del poeta. Entre los nombres de personas ya hemos comentado la invención de algún

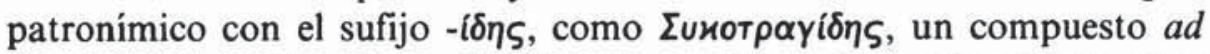

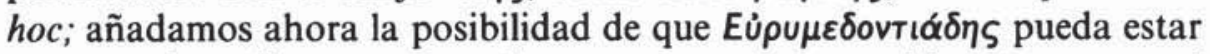
en esta misma línea, aunque el contexto no sea tan evidente como en el ejemplo anterior. Sobre el sentido del nombre femenino Ku$\psi \omega \dot{~ p a r e c e ~ q u e ~}$ no hay ninguna duda, aunque sólo sea por la frecuente utilización con valor obsceno del radical correspondiente. Junto a estos nombres de doble sentido claro, creemos debe tenerse en cuenta la posibilidad de que el significado de algunos otros también pueda ser susceptible de esa interpreta-

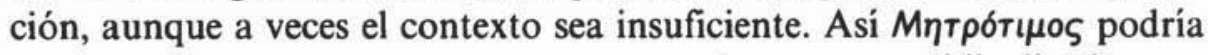
contener una alusión a inclinaciones poco honestas ya ridiculizadas por el propio Hiponacte; incluso algunos han propuesto un carácter ficticio

59 «Nomi e sopranomi archilochei», $M H 37,1980$, pp. 65-88. 
equívoco para el nombre $\Pi \alpha v \delta \omega ́ \rho \eta^{60}$, en paralelo con la $\Pi \alpha \sigma \iota \phi i \lambda \eta$ de Arquíloco ${ }^{61}$.

Un doble sentido evidente es el que presentan algunos topónimos, como $\Pi u \gamma \varepsilon \hat{\varepsilon} \lambda \alpha \iota$ y $K \alpha \mu \alpha v \delta \omega \lambda{ }^{\prime} \varsigma^{62}$ : Entre los gentilicios y los de origen mere-

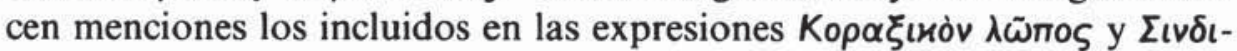

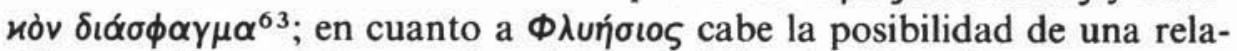
ción con alguno de los sentidos de la raíz del verbo $\phi \lambda u ́ \omega^{64}$.

3. Contenido y estructura. Ni el puro nivel léxico, ni siquiera el más amplio del lenguaje en general, son los únicos que nos sitúan ante un fenómeno literario que ya puede decirse que contiene el germen de la comedia. La aparición coincidente de un número de palabras en dos autores de épocas diferentes ha de ser manejada con precaución, por muy alto y significativo que aquél sea, y desde luego su aparición aislada tiene muy escaso valor probatorio. Sí lo posee, en cambio, la presencia de ese rasgo junto a otras similitudes que afectan a unidades de estructura y, sobre todo, de contenido. No obstante, podría admitirse una restricción (casi superflua en todo estudio comparativo): la posibilidad de que condiciones y circunstancias similares hayan conducido a resultados también similares. Argumento al que, sin duda, podemos darle la vuelta: sin ese contexto apropiado tampoco habría triunfado un género que, por esa misma razón, desarrollaba elementos tradicionales a disposición del autor, aunque el nivel de consciencia en su utilización sea variable.

3.1. Pensemos, por ejemplo, en la temática de tipo obsceno. Ya de por sí es éste un concepto difícil de precisar cuando tratamos de sociedades y de épocas diferentes. No se trata, en verdad, de pensar que entre

${ }^{60}$ Cf. Medeiros, op. cit., p. 158.

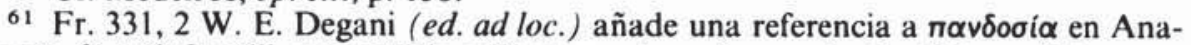

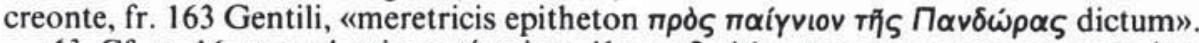

${ }^{62} \mathrm{Cf}$. n. 16 para el primer término; $K \alpha \mu \alpha v \delta \omega \lambda \delta \varsigma$ parece querer apurar un juego de palabras sobre $\chi \alpha \mu \alpha i$. El verso en el que aparece (fr. 124) sirvió, según Sexto Empírico (Adu. math. I 275), para dirimir un litigio por la posesión de ese territorio (denominado en el tex to Camandodo).

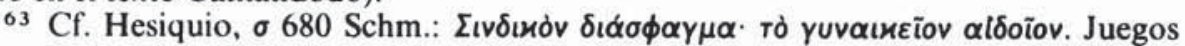
de palabras semejantes se encuentran en el propio Aristófanes: cf. Lis. 87, 91, 1163 , 1169 s., etc.

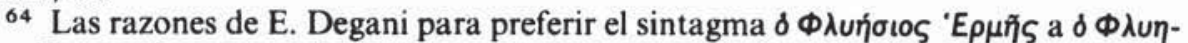
$\sigma i \omega v{ }^{~} E \rho \mu \tilde{\zeta}$ (lo que conduce a un nuevo planteamiento métrico, reflejado en su edición) deben tenerse en cuenta («Problemi di lessicografia greca», BIFG 4, 1977/78, pp. $135-146=$ «Problems in Greek Lexicography, MPhL 4, 1981, pp. 1-14). En cuanto a la relación con el verbo $\phi \lambda u ́ \omega$, fue apuntada ya por E. Romagnoli, I poeti lirici, Bolonia $1950_{3}$, p. 204. Más sugerencias en Medeiros, op. cit., p. 34. 
los jonios del siglo vi o los atenienses del siglo v careciera de efecto la expresión de este tipo de ideas y la utilización de ese lenguaje como si estuviéramos ante individuos completamente amorales o libres de tabúes. Precisamente porque no es así, la crudeza de ese lenguaje tiene un efecto, que no es, desde luego, el del taco o la obscenidad en un casto oído; creemos que no es necesario repetir ahora las conocidas ideas acerca de los orígenes rituales de este tipo de poesía o del teatro o sobre lo que supone la escrología en ese contexto religioso. Más interesante, en todo caso, es tener presente el valor que semejante procedimiento, aplicado a la poesía, tiene desde un punto de vista psicológico en el triángulo poeta (o personaje $\mathrm{A}$, que hace víctima de lo obsceno a otro) -auditorio-víctima (o personaje B), como ha destacado J. Henderson ${ }^{65}$.

3.2. Ahora bien, como esa temática obscena puede dejar aún sospechas de elemento coincidente $a b$ origine, creemos necesario ampliar la exposición a otros aspectos menos dudosos si cabe. Es dificil resistirse a la tentación de hablar de un "héroe cómico» o, al menos, de una variante o fórmula escueta en el yambo de tan elemental componente de la comedia $^{66}$. En realidad, deberíamos hablar más bien de un "antihéroe» en el yambo ${ }^{67}$. Mayoritariamente parece que hemos de pensar en el propio poeta; pero, incluso aunque nos mostráramos radicales en el problema de la "self-expression", la diferencia no sería esencial para la idea expuesta. Al fin y al cabo se ha de reconocer que en diversos fragmentos (centrándonos ahora en Hiponacte) hay un protagonista que, por la utilización de la primera persona, puede ser el poeta, descrito como centro de acciones no precisamente gloriosas y con variados resultados. En otro lugar ${ }^{68}$ hemos señalado una diferencia esencial entre, por ejemplo, fragmentos de Arquíloco como el del célebre P.Col. 7511 o P.Oxy. 2310 y otros de Hiponacte, como los números 84, 92 y 104 . En el cotejo se nos aparecen los

${ }^{65}$ Op. cit., p. 2 ss., especialmente p. 10.

${ }^{60}$ Es claro que estas afirmaciones se han de entender en su justa medida, por el estado y naturaleza de los textos hiponacteos. Sobre el tema de Aristófanes vid. C.H. Whitmann, Aristophanes and the Comic Hero, Cambridge 1964, y las más recientes observaciones de J.L. Navarro, "La estructura interna del héroe cómico», CFC 15, 1978, pp. 137-166; cf. asimismo G. Nagy, The Best of the Achaeans. Concepts of the Hero in Archaic Greek Poetry, Baltimore/Londres 1979, pp. 251-252, acerca de la persona poética a propósito de Arquíloco y la comedia, con la asunción del papel de la «blame» por el actor.

67 En este sentido se justifica el planteamiento del poeta yámbico como «trickster» sostenido por C. Miralles y J. Pòrtulas, op. cit., pp. 9-50.

68 "Arquiloco, entre la mímesis y la ironia, Actas del I Congreso Andaluz de Estudios Clásicos, Jaén 1982, pp. 444-450. 
textos de Hiponacte como mucho más directos y menos alusivos, más dominados por una acción y destinados a un publico «más proclive a la carcajada ante una escena descrita de forma realista, que a la sonrisa ante una sutil utilización de un diálogo "convencional'». Asimismo, señalábamos a este propósito la similitud de esta formalización "dramatizada» de la acción con la de numerosas escenas de la comedia. Pues bien, añadimos ahora, hay una concepción de «lo cómico» en la descripción de esas escenas muy similar a la que se encuentra en un Aristófanes: el poeta se ve en situaciones tan gloriosas como las del fr. 92, que parece concluir en una generosa defecación, igual que un Mnesíloco se ve envuelto, por ejemplo, en la operación de depilación de sus partes que se describe en Tesm. 236. Aún pueden establecerse otras referencias: Mnesíloco teme por la

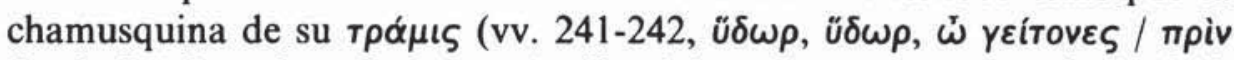

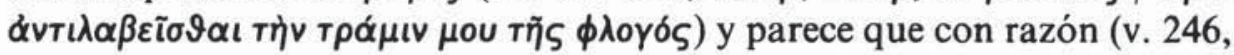

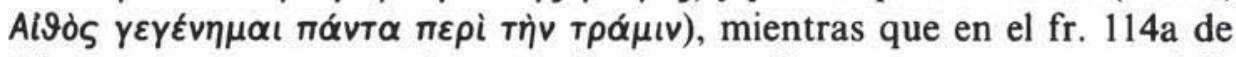
Hiponacte se expresa un deseo malévolo que afecta a parte tan poco subli-

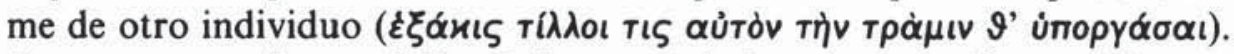
Por otra parte, la aparición de los escarabajos y su relación con el tema escatológico en el fr. 92 nos remite en seguida al prólogo de $\mathrm{Paz}^{69}$. La animación del fr. 104 anticipa algunos vivaces agones de comedia, etc.

3.3. El lector de Aristófanes capta inmediatamente una especie de "familiaridad respetuosa» en la manera de referirse a los dioses, en las plegarias y, más aún, en su participación directa a veces en la acción. No vamos a afirmar tajantemente que el caso de Hiponacte sea idéntico, pero tampoco es dificil ver el atisbo de una actitud semejante. Los dioses que aparecen en Hiponacte son Zeus, Hermes, Malis (quizá identificable con Atenea), Apolo, Dioniso, Cíbele (Cíbebe) y Bendis, de una dudosa alusión a Posidón. Aparte del posible sincretismo cultural y religioso que pueda denotar esta enumeración ${ }^{70}$, lo más interesante es que el contexto normal en que aparecen mencionadas esas divinidades es la plegaria en tono humorístico. Es decir, por un lado, el sentimiento religioso aquí expresado muestra una vez más una raíz popular que dota de una peculiar formaliza-

\footnotetext{
69 Más aún: Romagnoli, op. cit., pp. 224-225 y 232-235, ya había apuntado la estrecha relación con la escena configurada en Nubes 709-714, protagonizada por Estrepsíades. La asociación $\lambda \alpha u ́ \rho \alpha-\varkappa \alpha ́ v \vartheta \alpha \rho o \iota$ en $P a z$ ha sido subrayada por F. Bossi, a propósito del fr. 78 («Nota a Hippon. fr. 78, 12 W», QUCC 21, 1976, pp. 27-28.

70 En realidad Bendis es divinidad tracia; cf. W. Burkert, Griechische Religion der archaischen und klassischen Epoche, Stuttgart/Berlín/Colonia/Maguncia 1977, p. 278 y, sobre Cíbele y Cíbebe, p. 276.
} 
ción a la plegaria, en la que interviene a veces alguna tradición suficientemente atestiguada. Algunos de los fragmentos en que se acumulan más rasgos de lenguaje de nivel coloquial son precisamente plegarias a Hermes, el dios que encontramos mencionado con más frecuencia en Hiponacte: un Hermes calificado de «ahorcaperros», a quien el poeta pide ayuda con frecuencia, un dios "compañero de ladrones» ${ }^{71}$, de vagabundos y miserables. Incluso las plegarias a dioses más «olimpicos», como Zeus o esa posible versión de Atenea denominada Malis, están dotadas de cierta uis comica ${ }^{72}$. En resumen, también estos datos apuntan a una "Gebetsparodie», a esa parodia de la plegaria tan cara a la comedia ${ }^{73}$, que aquí podría considerarse ya en ciernes. Por otra parte, el sentimiento religioso encuentra rápidamente cauces que se salen de las creencias más o menos oficiales y que se manifiestan de modo similar en diferentes épocas. Encontramos aquí alusiones a divinidades secundarias y fiestas locales,

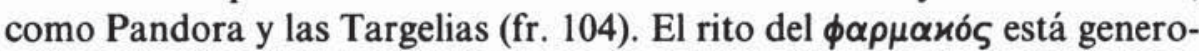
samente atestiguado ${ }^{74}$. También en el fr. 104 se habla de una aplicación de $\beta \dot{\alpha} \varkappa \varkappa \alpha \rho ı \varsigma$ que podría responder a un tipo de rito (aunque es problemático); y no falta cierta mezcla de magia y medicina popular en el fr. 92, tan "cómico" en toda su constitución, según hemos señalado, con un conocido paralelo en el banquete de Trimalción ${ }^{75}$.

4. Varia. Tampoco faltan puntos de contacto con la comedia aristofánica incluso en algo tan difícil aparentemente como es la temática, y no sólo en la mera utilización de motivos aislados. En efecto, el tema proverbial de la ceguera de Pluto, que merece en Aristófanes toda una come-

71 Sobre este aspecto de Hermes, además de N.O. Brown, Hermes the Thief, Nueva York 1947, véase Burkert, op. cit., pp. 244-245, y la interpretación de C. Miralles-J. Pòrtulas, op. cit., passim, especialmente el capítulo IV.

72 Zeus es invocado como 'O $\lambda u \mu \pi i \omega \omega v \pi \alpha \lambda \mu \nu$ (fr. 38,1), reprochándole no conceder oro; con acierto trae a colación Medeiros Arist. Plut. 130-134, a propósito de este frag-

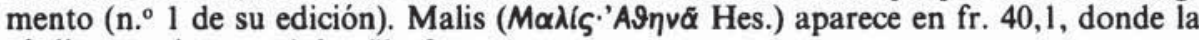

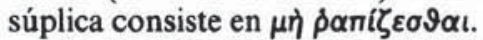

${ }^{73}$ Es obligada la cita de H. Kleinknecht, Die Gebetsparodie in der Antike, Stuttgart 1937; y, para Aristófanes, W. Horn, Gebet und Gebetsparodie in den Komödien des Aristophanes, Nuremberg 1970.

${ }_{74}$ Además de la aparición expresa del término en diversos fragmentos (cf. «Índice", ap. 3) debe tenerse en cuenta la reciente interpretación de C. Miralles del fr. 78 , en el sentido de que el personaje del mismo pueda considerarse un $\phi \alpha \rho \mu \alpha \varkappa \delta \varsigma$ ( $« \mathrm{Il} \mathrm{fr}$. 78W di Ipponatten, QUCC 14, 2, 1983, pp. 7-16).

75 La primera observación en este sentido proviene de K. Latte, "Hipponacteum", Hermes 64,1929 , pp. 385-388 (=Kl. Schr., pp. 464-467). Véanse comentarios y sugerencias diversas en las ediciones de Adrados, p. 51; Medeiros, pp. 102-106; Masson, pp. 150-152; Degani ad loc., así como en West, op. cit. en n. 43, pp. 144-145. 
dia, se trata en el fr. $36^{76}$, con una formulación que no carece de paralelos tanto en el propio Aristófanes como en otros comediógrafos áticos.

Que el yambo haga de ciertas personas el centro de su invectiva es un rasgo casi "supragenérico», que no implica en absoluto dependencia, pero sí afinidad. Ahí están víctimas como Atenis, Búpalo o Arete, puestos en cruda evidencia, como en Aristófanes lo estarán un Cleón o un Sócrates, salvando las diferencias "dimensionales». Incluso no falta, parece ser, la invectiva literaria, como podría desprenderse de la noticia, que acompaña al fr. 163, respecto de Mimnermo ${ }^{77}$.

También Hiponacte, como más tarde Aristófanes, dispone de una serie de nombres usados de manera casi tópica y que constituyen una especie de «Leitmotiv» de modelos negativos. En Aristófanes, por ejemplo, hay figuras de la música y de la literatura que, no sólo como centro de auténticos ataques frontales (caso de un Eurípides o un Agatón), sino también en frecuentes "chispazos" o alusiones aisladas, nos revelan una serie de fobias o gustos del autor. Pues bien, algo similar ocurre con el músico Códalo en Hiponacte $^{78}$ y, sobre todo, con Cicón (Kix $\left.\omega v\right)$ mencionado en el fr. 118 junto con Códalo, a propósito de un acompañamiento de flauta, pero que es el nombre que corresponde a un adivino de poca fortuna en sus predicciones, según se deduce de los fragmentos 4 y 4 a. Por último, otro flautista de poca fortuna mencionado por Hiponacte parece que fue Babis $(B \alpha \beta \tilde{u} \varsigma)^{79}$.

5. Creemos, en fin, que, a la vista de los datos aquí analizados, se corrobora la hipótesis de partida, es decir, la presencia in nuce en el yambo arcaico de elementos que serán constitutivos de la comedia ática y que nos permiten casi calificar a Hiponacte como «el más cómico» de los yambógrafos. Bien entendido que la aparición de estos rasgos en la escena no supondrá más que una célula de ese irrepetible y complejísimo género, quizá el testimonio más genial de la vida griega y de su cultura, que es el teatro $\mathrm{y}$, consecuentemente, la comedia.

\section{EMILIOSUÁREZ de LA TORRE}

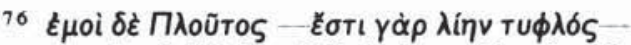

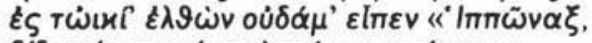

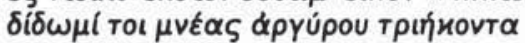

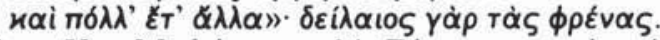

Cf. n. 59 y Medeiros, p. 14. Diversos pasajes similares de comedia son aducidos por E. Degani, ed. ad loc.

77 Aunque el tenor del texto plutarqueo (De mus. VIII, p. $1133 \mathrm{f}$ ) no aclara demasiado al respecto.

${ }_{78} \mathrm{Fr} .118$ y $151 \mathrm{a}($ dub.).

79 Fr. 153 Degani (148 Medeiros). Cabe la posibilidad, no obstante, de que tanto Babis como Códalo sean personajes «paremíacos». 


\section{LÉXICO COMENTADO*}

\section{COMPUESTOS}

\begin{tabular}{|c|c|c|}
\hline$\alpha v \alpha \sigma \varepsilon ı \sigma i \phi \alpha \lambda \lambda \lambda_{\circ}$ & 135 & \\
\hline 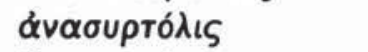 & $135 \mathrm{a}$ & \\
\hline$\beta \alpha \sigma \alpha \gamma ı x \delta \rho \circ$ & 139 & \\
\hline Ворßоро́тп & $135 a$ & \\
\hline 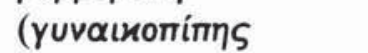 & 118,16 M.) & \\
\hline$\varepsilon \gamma \gamma \gamma \alpha \sigma \tau \rho \iota \mu \alpha \dot{\chi} \chi \alpha \iota \rho \alpha$ & 128,2 & \\
\hline 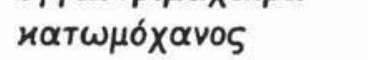 & 28,1 & \\
\hline 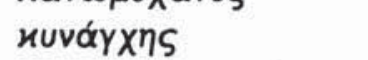 & $3 a, 1$ & \\
\hline & 114 & \\
\hline$\pi \alpha \sigma \pi \alpha \lambda \eta \phi \alpha \gamma \circ \varsigma$ & 103,11 & $(\pi \alpha \sigma \pi \alpha \dot{\alpha} \eta$ Av. 91) \\
\hline поvтох $\alpha \rho \cup \beta \delta ı \varsigma$ & 128,1 & \\
\hline$\sigma \pi \circ \delta \eta \sigma \iota \lambda \alpha u ́ \rho \alpha$ & $195 \mathrm{a}$ & \\
\hline бинотраүі́іпs & 134 & \\
\hline 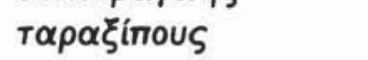 & 104,46 & 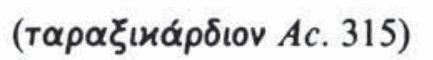 \\
\hline 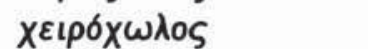 & 139 & 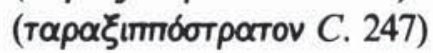 \\
\hline
\end{tabular}

\section{LENGUAJE OBSCENO}

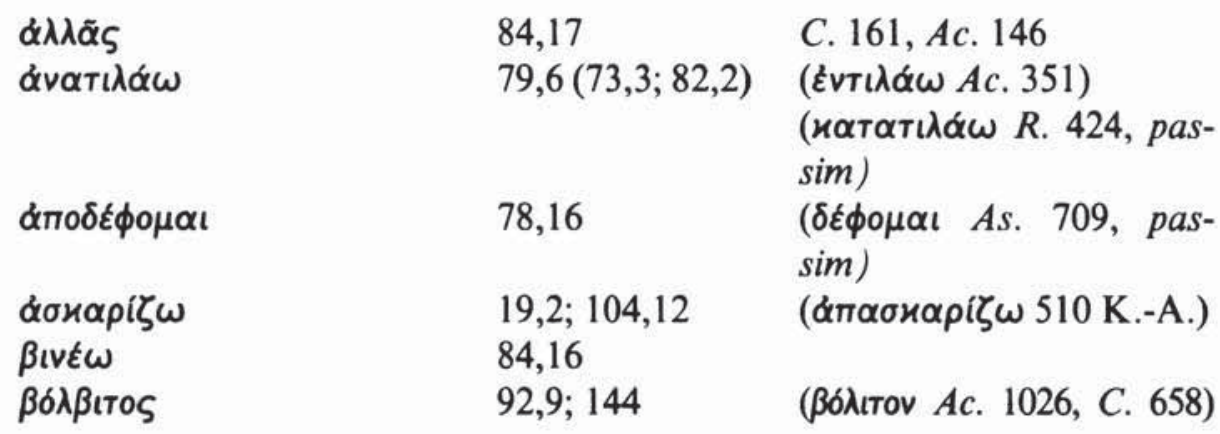




\begin{tabular}{|c|c|c|}
\hline ßорßоро́тп & 135 & 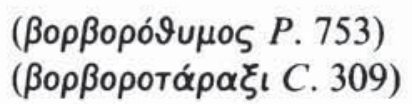 \\
\hline 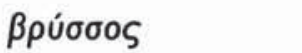 & 70,8 & \\
\hline$\gamma \lambda \eta \chi \omega \dot{ }$ & 84,4 & $(\gamma \lambda \alpha \chi \dot{\omega} A c .869)$ \\
\hline$\delta ı \alpha \sigma \phi \alpha \gamma \mu \alpha$ & 26 & \\
\hline 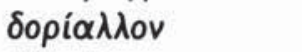 & 174 & fr. 382 K.-A. \\
\hline 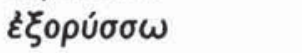 & 104,35 & Ac. 763 \\
\hline EỦvoũXoS & 26,3 & Ac. 121 (cf. $A c .117)$ \\
\hline 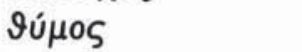 & 10 & \\
\hline løxás & 8,$1 ; 124$ & \\
\hline 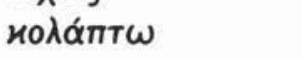 & 21 & \\
\hline 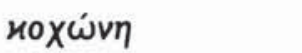 & $151 b$ & C. 424 , etc. \\
\hline 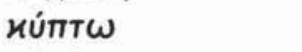 & 17 & \\
\hline 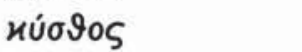 & 174 & Ac. 782 , passim \\
\hline$\varkappa \omega \lambda \tilde{\eta}$ & 75,1 & N. 989 , etc. \\
\hline$\lambda \alpha u ́ p \eta$ & $61 ; 92,10 ; 155$ & P. 99,158 . \\
\hline$\lambda \varepsilon \iota \mu \omega \dot{\omega} \nu$ & 6 & \\
\hline$\lambda \tilde{\omega} \pi о \varsigma$ & 2 & \\
\hline ни́ртоS & 174 & \\
\hline$\mu v \sigma \alpha \dot{\chi} \chi \eta \eta$ & 105,10 & \\
\hline$\delta \mu \varepsilon i \chi \chi \omega$ & 73,3 & \\
\hline борхı५ & 92,3 & L. 963, passim \\
\hline пршито́ & 104,32 & C. 78, passim \\
\hline$\pi \cup \gamma \varepsilon \omega \dot{v}(\pi u \gamma เ \sigma \tau i)$ & 92,15 & (пиүฑ́ T. 1187, passim) \\
\hline$\sigma \varkappa u \lambda \varepsilon u ́ \omega$ & 70,8 & \\
\hline 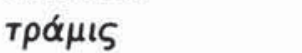 & $114 \mathrm{a}$ & T. 246 \\
\hline$\phi \alpha ́ \lambda \eta \varsigma$ & $21 ; 92,3$ & \\
\hline xoĩpos & 174 & Ac. 781 , passim \\
\hline
\end{tabular}

3. LENGUAJE COLOQUIAL (CON POSIBLES JONISMOS; 2.3.12.3.2)

\begin{tabular}{|c|c|c|}
\hline 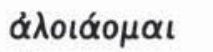 & 79,2 & \\
\hline$\alpha \rho \rho \iota x \alpha \dot{\alpha} \circ \mu \alpha \iota$ & 137 & $(\alpha v \alpha \rho \rho \iota \chi \alpha \dot{\alpha} о \mu \alpha \iota$ P. 70) \\
\hline$\alpha \sigma x \varepsilon \rho \eta$ & 34,3 & \\
\hline$\alpha \phi \eta \dot{~}$ & 8,1 & \\
\hline$\beta \alpha \mu \beta \alpha \lambda u ́ \zeta \omega$ & 32,3 & \\
\hline$\beta \alpha T T \alpha \rho i \zeta \omega$ & 140 & \\
\hline 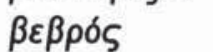 & 40,1 & \\
\hline 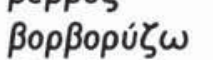 & $29 a$ & \\
\hline$\beta \rho \varepsilon v \vartheta \dot{o} \mu \alpha \iota$ & 141 & N. 362, L. 887, P. 26 \\
\hline
\end{tabular}




\begin{tabular}{|c|c|c|}
\hline 136 & EMILIO SUÁRE & \\
\hline 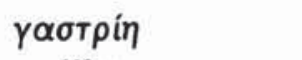 & 118,9 & $(T .484)$ \\
\hline 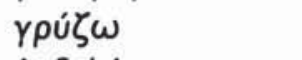 & 70,6 & P. 97 \\
\hline$\varepsilon \varkappa \delta \iota \phi a ́ \omega$ & 85,8 & \\
\hline$\varepsilon \mu \beta \alpha \beta \alpha \dot{\alpha} \zeta \omega$ & 53 & \\
\hline$\varepsilon \xi \alpha \rho \alpha \dot{\sigma} \sigma \sigma \omega$ & $22 \mathrm{a}$ & T. 704 \\
\hline$\varepsilon \pi \sqcap ß \rho u ́ x \omega$ & 104,15 & 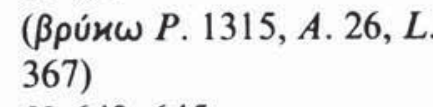 \\
\hline 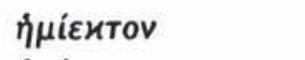 & 21 & N. 643,645 \\
\hline п्रіичпроv & $148 \mathrm{a}$ & \\
\hline эं் $\pi \omega$ & 12,1 & \\
\hline ห $\alpha \Pi \eta \lambda \varepsilon u ́ \omega$ & 79,18 & 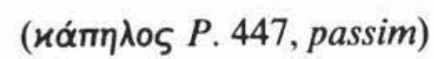 \\
\hline и $\alpha т \alpha \lambda і \sigma \sigma \sigma \omega$ & 104,16 & (fr. 205,3-4 K.-A.) \\
\hline 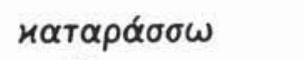 & 13,$2 ; 104,7$ & \\
\hline 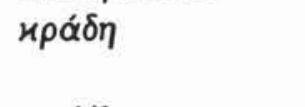 & $\begin{array}{l}5 ; 6,2 ; 9,2 \\
92,4,7\end{array}$ & A. 40, P. 627 \\
\hline$\kappa \rho \dot{\omega} \zeta \omega$ & 61 & A. 2 \\
\hline nuptos & 117,3 & \\
\hline 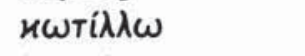 & 102,1 & \\
\hline$\lambda \alpha \iota \mu \alpha \alpha \omega$ & 118,3 & A. 1563 \\
\hline$\lambda \alpha \sigma \vartheta \alpha i v \omega$ & 104,14 & \\
\hline$\mu \alpha \delta \alpha \dot{\alpha} \omega$ & 24 & Pl. 266 \\
\hline$\mu \alpha \rho i \lambda \eta$ & $\begin{array}{l}59,1 ; 78,9 \\
78 \mathrm{a}\end{array}$ & Ac. 350 \\
\hline 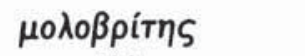 & $114 \mathrm{~b}$ & \\
\hline$\mu \circ \iota \mu \dot{\lambda} \lambda \lambda \omega$ & 124 & C. $A d .1080 \mathrm{~K}$. \\
\hline$\mu v \lambda \alpha и р і \varsigma$ & 162 & \\
\hline$\mu \dot{\xi} \xi \alpha$ & 22 & \\
\hline$\delta \mu \phi \alpha \lambda \eta \tau \delta \mu \circ$ & 19,1 & \\
\hline$\delta \phi \varepsilon \lambda \lambda \omega(\delta \phi \varepsilon \lambda \mu \alpha)$ & 79,19 & \\
\hline$\pi \alpha \mu \phi \alpha \lambda \alpha \omega$ & 164 & \\
\hline$\pi \varepsilon \lambda \lambda \eta$ ( $\pi \varepsilon \lambda \lambda i \varsigma)$ & $14,1(13,1)$ & \\
\hline$\pi \varepsilon \rho \iota \psi \alpha ́ \alpha \omega$ & 104,18 & P. 909 \\
\hline поvтрós & 49,1 & P. 181, passim \\
\hline$\rho \alpha \pi i \zeta \omega$ & 102 & \\
\hline $\dot{\phi} \cup \dot{\varepsilon} \omega$ & 165 & 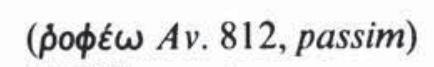 \\
\hline бапрós & 24 & P. 698, passim \\
\hline$\sigma \alpha \rho \mu \delta \varsigma$ & $165 \mathrm{a}$ & \\
\hline$\sigma i \phi \omega v$ & 56 & \\
\hline$\sigma \varkappa \alpha \pi \alpha \rho \delta \varepsilon u ́ \omega$ & $3 \mathrm{a}, 2$ & \\
\hline биірафоs & $129 a$ & \\
\hline
\end{tabular}




\begin{tabular}{|c|c|c|}
\hline био́тоక & 79,$18 ; 122$ & \\
\hline 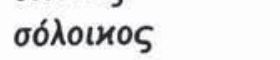 & 27,1 & \\
\hline 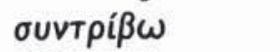 & 102,11 & Ac. 284, N. 1127 \\
\hline$T i \lambda \lambda \omega \omega$ & 114 & A. 365 , passim \\
\hline$\tau \rho \omega ́ \gamma \omega$ & 26,$5 ; 66$ & P. 1324, passim \\
\hline$\dot{U} \phi \varepsilon \hat{\varepsilon} x \omega$ & 12,3 & A. 187, passim \\
\hline$\phi \alpha \rho \mu \alpha$ иós & $\begin{array}{r}6,2 ; 7 ; 8,2 ; 9,2 ; \\
10,2 ; 92,4 ; 104,49\end{array}$ & R. 733 , passim \\
\hline 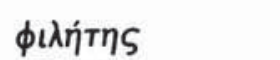 & 79,$10 ; 102,12$ & \\
\hline$\phi о \rho \mu i o v$ & 170 & (форні́ Av. 58) \\
\hline$\phi \circ \tilde{\delta} \delta \varepsilon \varsigma(\phi \omega \tilde{\delta} \delta \varepsilon \varsigma)$ & 59,1 & Pl. 535... \\
\hline$\phi \tilde{\omega} \rho$ & 3,$2 ; 117,8$ & \\
\hline 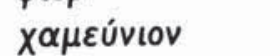 & 62 & $(\chi \alpha \mu \varepsilon u ́ v \eta n$ A. 816) \\
\hline 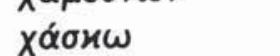 & 9,1 & A. 1493 \\
\hline 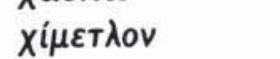 & 34,4 & Av. 1167 \\
\hline 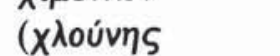 & 22 M.) & \\
\hline
\end{tabular}

\section{PRÉSTAMOS Y SUBSTRATO}

\begin{tabular}{|c|c|}
\hline$\ddot{\alpha} \beta \delta \eta \varsigma$ & 130 \\
\hline$\alpha \lambda i \beta \alpha \varsigma$ & 134 \\
\hline 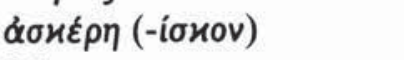 & 34,3 \\
\hline$\beta \alpha \dot{x} x \alpha \rho ı \varsigma$ & 104,21 \\
\hline ßÉนо丂 & 125 \\
\hline$\beta$ เี้น०ธ & 142 \\
\hline 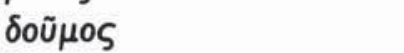 & 30,2 \\
\hline ह̌ & 79,8 \\
\hline 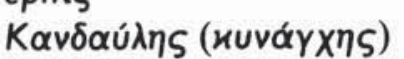 & 3,1 \\
\hline$\mu \alpha u \lambda เ \sigma \tau \dot{\rho} \rho\llcorner o v$ & 160 \\
\hline vqvíatov & 163 \\
\hline vixúртаs & 28,5 \\
\hline$\pi \alpha \lambda \mu \cup \varsigma$ & $\begin{array}{r}3 ; 38,1 ; 42,4 ; \\
47,2 ; 72,7\end{array}$ \\
\hline$\pi \alpha u \tilde{v ı}$ & 79,16 \\
\hline$\sigma \alpha \beta \beta \alpha v v i$ & 28,5 \\
\hline$x \alpha \dot{\lambda}$ เs & 67 \\
\hline
\end{tabular}

5. CONDIMENTOS Y UTENSILIOS CULINARIOS

$\begin{array}{lcc}\alpha \lambda i \beta \alpha \varsigma & 134 & \\ \alpha \lambda \lambda \tilde{\alpha} \varsigma & 84,17 & \text { C. 207, passim }\end{array}$


138

EMILIO SUÁREZ

\begin{tabular}{|c|c|c|}
\hline$\ddot{\alpha} \lambda \phi ı т о \nu$ & 39,3 & C. 1359, passim \\
\hline ӑртоక & 12,$3 ; 115,8$ & L. 1207, passim \\
\hline 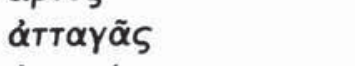 & 26,1 & A. 249 , passim \\
\hline ¿Travitis & 26,3 & \\
\hline 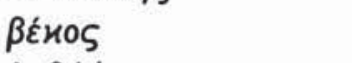 & 125 & 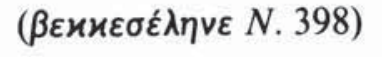 \\
\hline$\varepsilon \mu \beta \alpha \dot{\alpha} \phi ı v$ & 146 & \\
\hline हัTVOS & 29 & \\
\hline 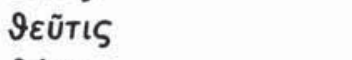 & 149 & 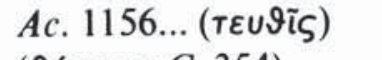 \\
\hline Yúvva & 26,2 & 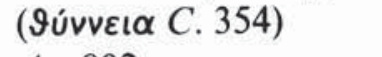 \\
\hline 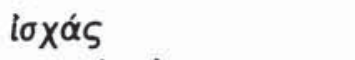 & 8,$1 ; 124$ & Ac. $802 \ldots$ \\
\hline иохии́ $\mu \eta \lambda$ 人。 & 60 & fr. $621 \mathrm{~K} . \mathrm{-A}$ \\
\hline 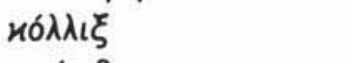 & 26,6 & 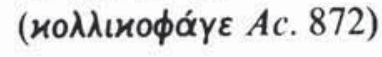 \\
\hline$\varkappa \rho \alpha \mu \beta \eta$ & 104,47 & \\
\hline 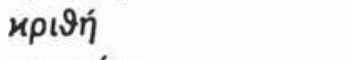 & 39,2 & P. 965 \\
\hline 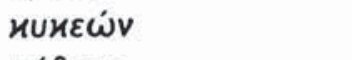 & 39,4 & \\
\hline หúগpos & $29 a$ & \\
\hline גaүós & $26 \mathrm{al}$ & \\
\hline 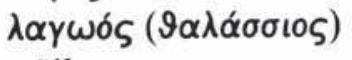 & 157 & \\
\hline$\mu \tilde{\alpha} \zeta \alpha$ & 8,1 & P. 565, passim \\
\hline 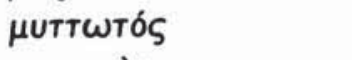 & 26,2 & \\
\hline$\pi \alpha \sigma \pi \alpha \lambda \eta-$ & 103,11 & Av. 91 \\
\hline 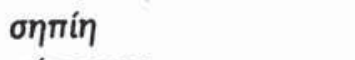 & 166 & Av. 91 \\
\hline$\sigma \dot{\eta} \sigma \alpha \mu \rho \nu$ & $26 \mathrm{a} 2$ & \\
\hline$\sigma x i \lambda \lambda \eta$ & 6,2 & \\
\hline 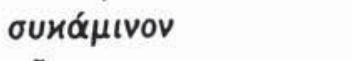 & 78,13 & \\
\hline бŨKov & 26,5 & P. 1324, passim \\
\hline тетракі́v & 168 & \\
\hline 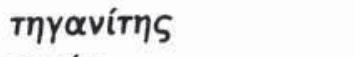 & $26 \mathrm{a} 2$ & \\
\hline Tupóv & 8,2 & \\
\hline$x \alpha \dot{\lambda} ı \varsigma$ & 67 & \\
\hline 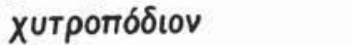 & 173 & \\
\hline
\end{tabular}

6. ANIMALES

\begin{tabular}{|c|c|c|}
\hline$\alpha \tau T \alpha \gamma \tilde{\alpha} \varsigma$ & $26 \mathrm{a} 1$ & Av. 257 , passim \\
\hline 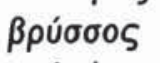 & 70,8 & \\
\hline үро́ $\mu ф ı \varsigma$ & 103,11 & frs. 333,$6 ; 520,6$ K.A. \\
\hline$\delta \varepsilon \lambda \phi \alpha \xi$ & 145 & \\
\hline$\varepsilon \rho \omega \delta ı \iota_{\varsigma}$ & 16,$2 ; 118,3$ & \\
\hline$\varepsilon \chi \chi เ \delta v \alpha$ & 79,11 & R. 473 \\
\hline ९દũTเS & 149 & Ac. 1156 \\
\hline
\end{tabular}




\begin{tabular}{|c|c|c|}
\hline ९úvva & 26,2 & C. 354 \\
\hline 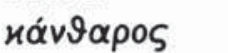 & 78,$12 ; 92,10,16$ & P. 45 , passim \\
\hline иариі́осо & 102,$11 ; 103,8$ & C. 608 , passim \\
\hline 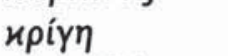 & 54 & \\
\hline 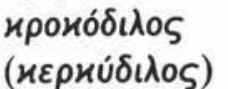 & $155 ; 155 \mathrm{a}$ & \\
\hline 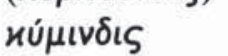 & 61 & A. 1181 \\
\hline หúwv & $\begin{array}{l}66 ; 79,10 ; 105,9 \\
115,11 ; 165\end{array}$ & \\
\hline 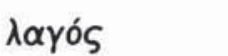 & $26 \mathrm{a} 1$ & C. 909 \\
\hline גís & 159 & \\
\hline$\mu \cup \tilde{\alpha} \alpha$ & 79 & Av. 597, passim \\
\hline ŏn $\phi ı \varsigma$ & $28,2,6$ & L. 759, passim \\
\hline піэпиоs & $155 \mathrm{a}$ & \\
\hline 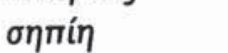 & 166 & A. 351 \\
\hline üxฑร & 169 & \\
\hline 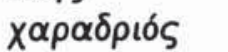 & 52 & A. 266 \\
\hline$x i \lambda i \alpha \gamma \rho \alpha$ & $172 \mathrm{a}$ & \\
\hline
\end{tabular}

\section{NOMBRES PARLANTES}
A. PERSONALES

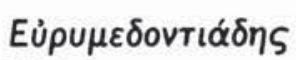

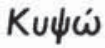

Мптро́тцоร

B. TOPÓNIMOS Y GENTILICIOS

\begin{tabular}{|c|c|}
\hline$K \alpha \mu \alpha v \delta \omega \lambda \delta \varsigma$ & 124 \\
\hline Кора & 2 \\
\hline 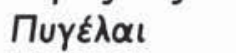 & 92,15 \\
\hline$\Sigma ı \delta_{1} \iota x \delta \varsigma$ & $2 a$ \\
\hline 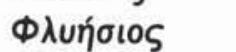 & 47,2 \\
\hline
\end{tabular}

En la columna central se da la numeración del fragmento en que aparece el término, según la edición de $\mathbf{M}$. L. West. En la columna de la derecha se relacionan los lugares aristofánicos en que dicho término se da de acuerdo con las siguientes abreviaturas: $A .=$ Aves; $A c .=$ Acarnienses; As. $=$ Asambleistas $; \quad$ Av $=$ Avispas $; \quad C .=$ Caballeros $; \quad L .=$ Lisistrata $;$ $N .=$ Nubes $;$. $=$ Paz; $P l .=P l u t o ; R .=$ Ranas $; T .=$ Tesmoforiantes . 